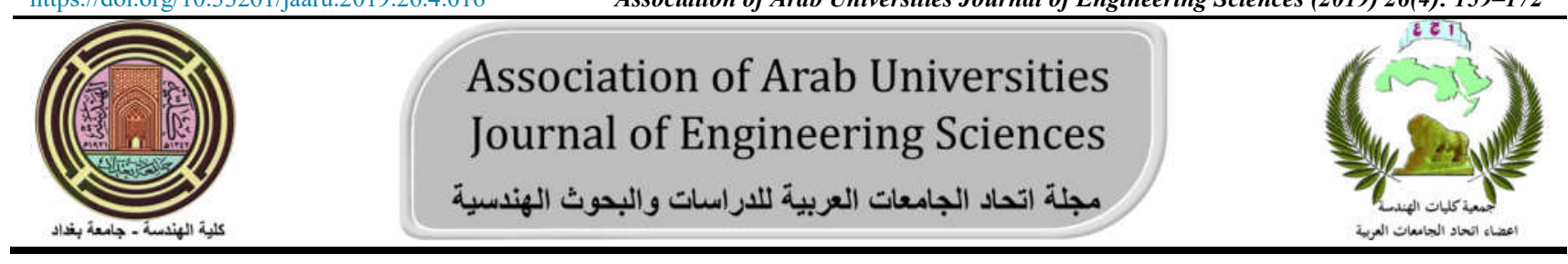

Association of Arab Universities Journal of Engineering Sciences

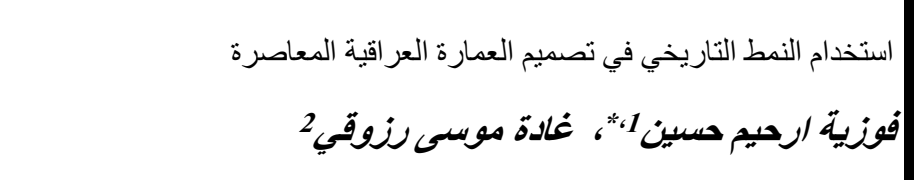

جامعة بغداد، كلبة الهندسة، قسم هندسة العدارة، fawziaasadi@coeng.uobaghdad.edu.iq

mrsghada@gmail.com جامعة بغداد، كلبة الهندسة، قسم هندسة العمارة،

fawziaasadi@coeng.uobaghdad.edu.iq الباحث الممثل: فوزية ارحيم حسبن، البريد الاكتتروني:

نشر في: 31 كانون الأول 2019

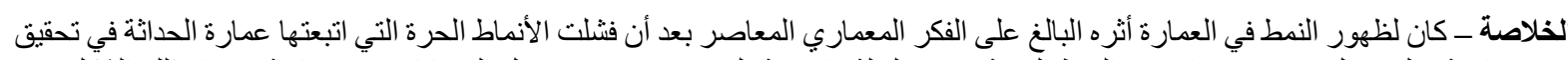

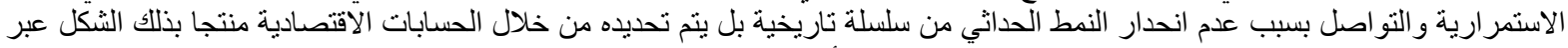

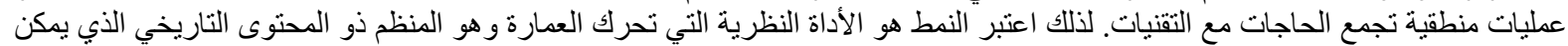

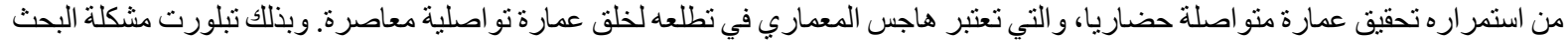

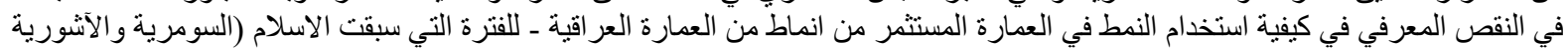

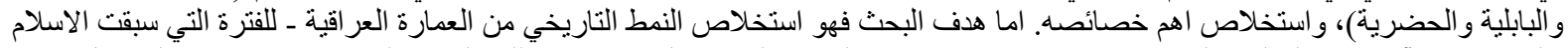

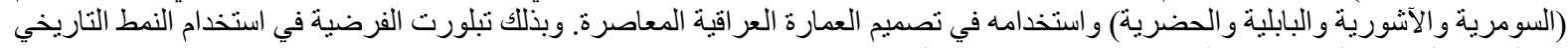

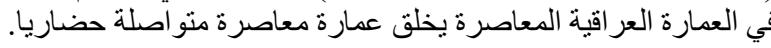

الكلمات الرئيسية ــ النمط، العمارة العر اقية، النمط التاريخي، العلاقات، العمارة المعاصرة.

1

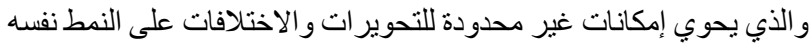

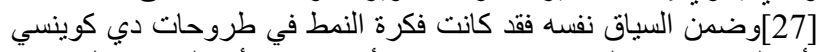

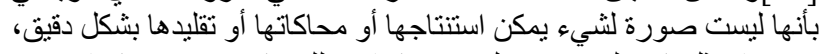

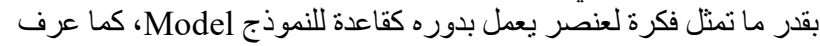

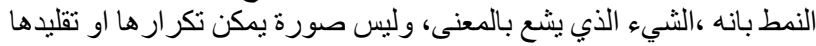

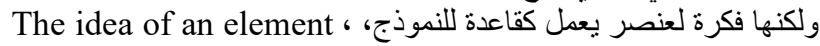
كما ان النمط

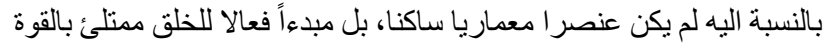

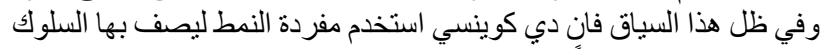

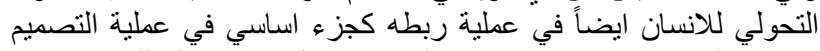

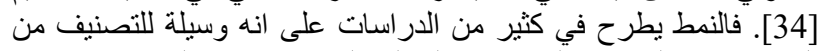

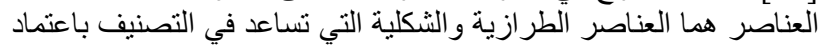

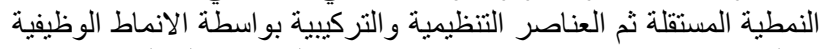
او الفضائية [1].وقد صنف دي كوينسي الانماط المعمارية الثكلية Formal Architectural typologies عملية التصميم وهي: - مئ

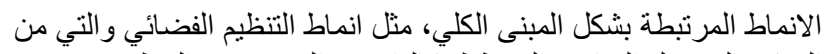

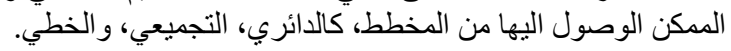

الانماط التي ترتبط بالعناصر الهيكلية الرئيسية، كانماط السقف المستوي،

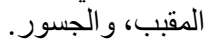

الانماط المرتبطة بالمعالجات السطحية للمبنى مثل نسق الاعمدة والمعالجات الزخرفية...الخ [27].

اما تصنيف Argan للنمط فقد قسمه الى ثلاثة فئات و هي: الفئة التي تختص بالابنية ذات التخطبط الطولي أولئية المركزي.

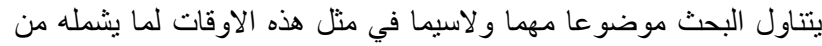

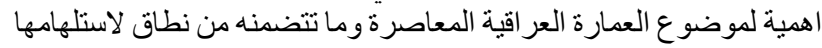

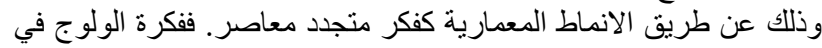

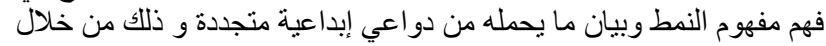

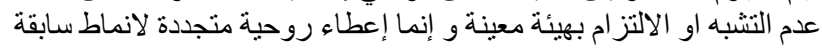

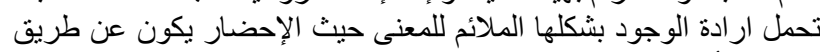

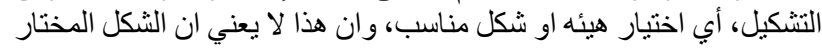

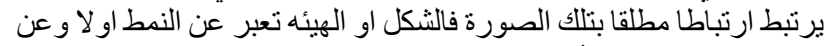

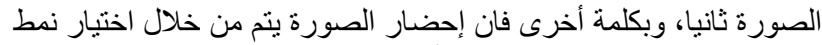

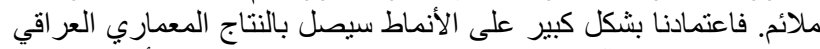

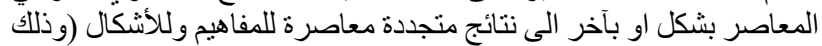

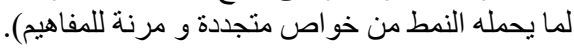

\section{Type 2}

يعرف النمط لغويا بانه الطريقة او الاسلوب و الجماعة من الناس امر هم و احد-

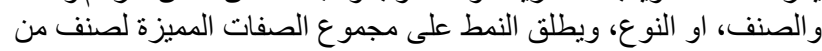

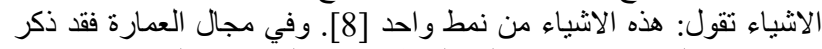

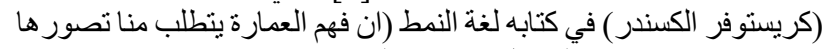

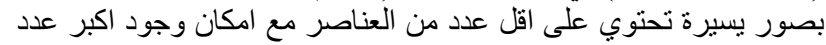

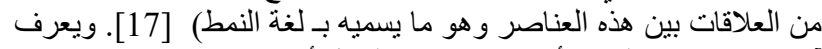

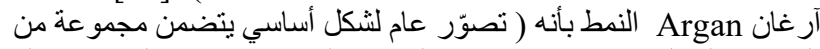

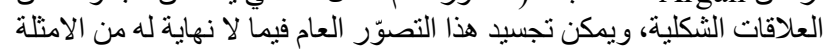

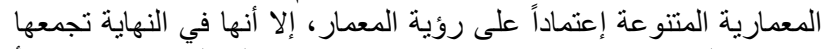

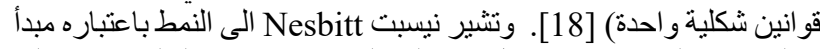

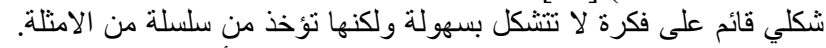

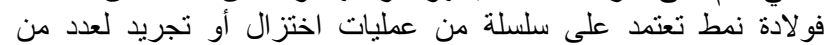

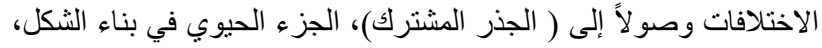


العلاقة بين الداخل والخارج يقع ضمن نظرتين: نظرة وظيفية تعتبر كثفا

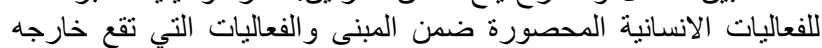

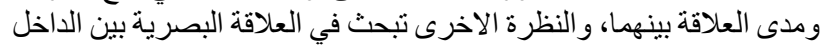

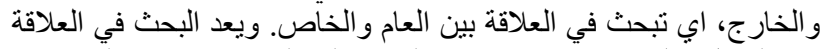

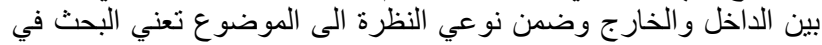

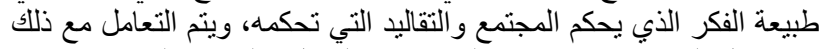
من خلال التصميم. فقد قسمت العلاقة بين الداخل والخيد الخارج الى ثناثة انماط

$$
\begin{aligned}
& \text { • الفصل التام بين الداخل و الخارج. } \\
& \text { • • • • • • } \\
& \text { التو افق بين الداخل و الخارج. }
\end{aligned}
$$

\section{العلاقات الانثائية}

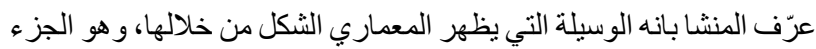

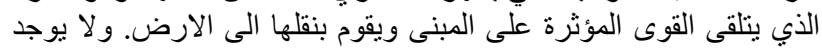

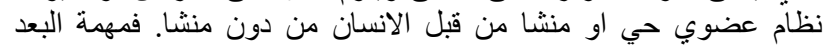

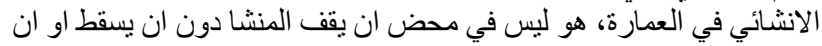

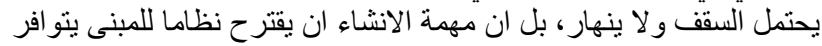

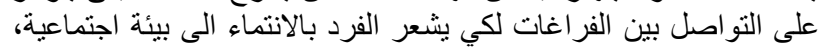

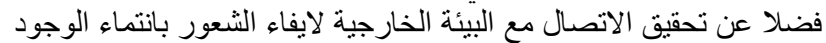

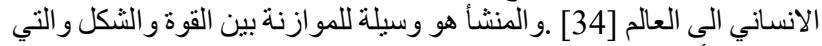

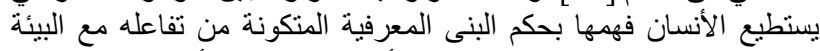

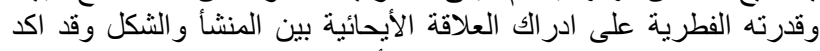

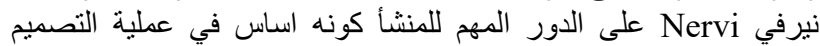

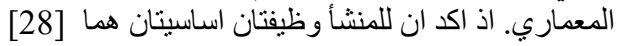
1-الوظيفة الأنشائية. 2-الوظيفة الجمالية و التعبيرية 2.4

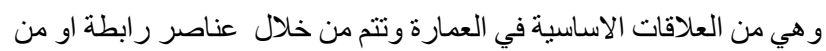

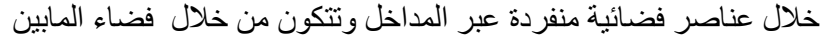

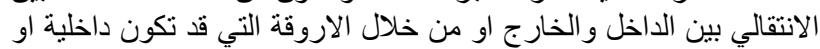
خارجية، فضلا عن الفناءات الداخلية الدارية.

\section{العلاقات الثانوية_الجزء (العناصر)}

تعد العناصر (Elements) في اي مجال بانها ،احدى المكونات الاساسية

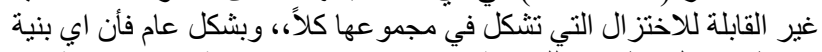

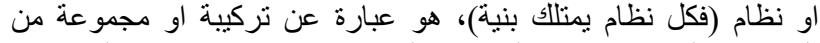

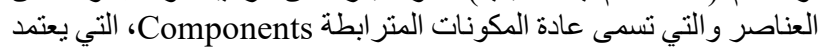

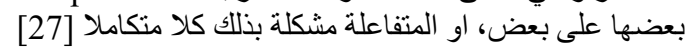

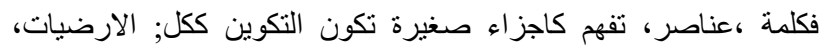

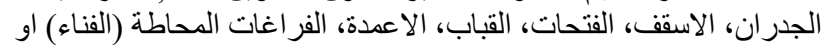

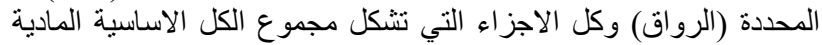

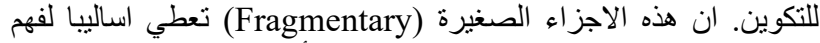

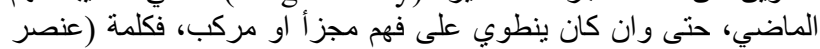

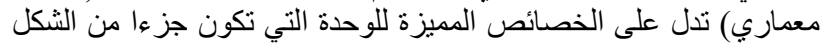

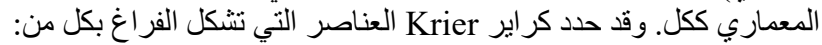

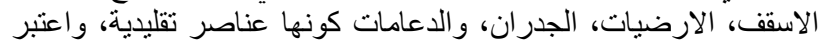

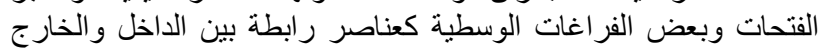

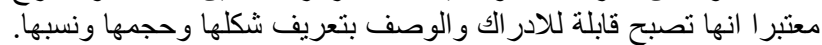

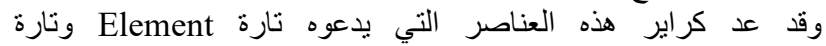

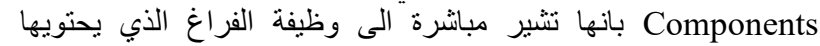

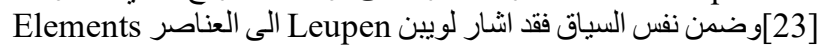

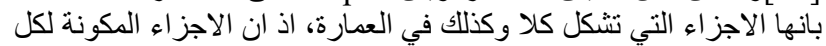

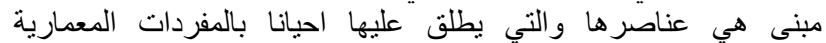
Architectural Vocabulary
الفئة التي تهتم بالعناصر التركيبية الرئيسية (كالسقوف المستوية او المائلة أو المدبية او المسطحة المنرة

• الفئة التي تهتم بعناصر الزخرفية (كتفصيل الزخرفة والتزيين) [17] وقد تناول بول فر انكل Paul Frankl موضوع تاريخ الانماط في العمارة

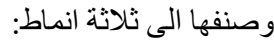

• النمط الفضائي Spatial Type: ويعنى باستنباط الانماط الاساسية للعلاقات الفضائية على مستوى المخطط عبر تحليل المخططات الإنية الارضية الإنية للانماط البنائية الاكثر شيو عائية على على مستوى الابنية الدينية.

• النمط المادي Corporeal Type: ويعنى بدر اسة الكتل وتمفصلها،

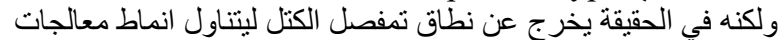

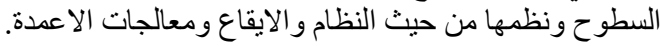

• النمط البصري Visual Type: ويقصد به القيم البصرية للواجهات

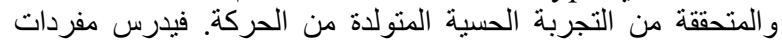

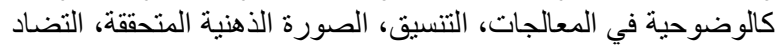

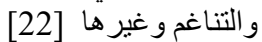

وعليه وحسب الطرح السابق وعند مقارنة وتحليل تصنيفات الثلاثة اعلاه

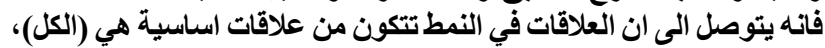

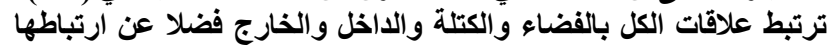

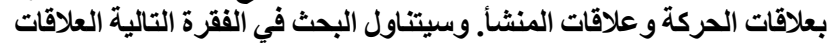
الثانوية للنمط ات الثركة

\section{العلاقات الاساسية (الكل)}

2.1

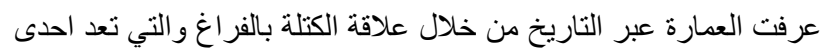

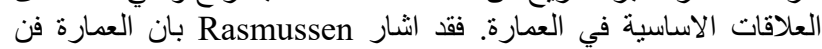

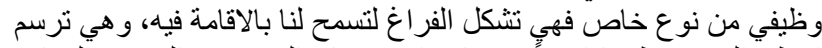

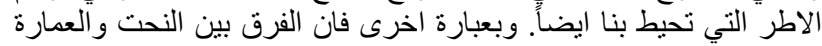

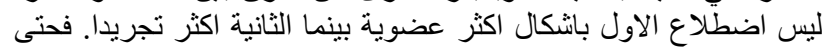

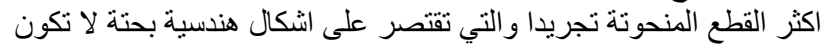

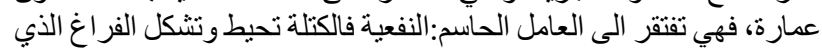

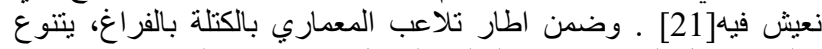

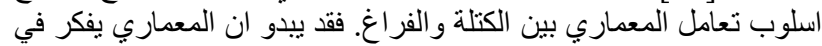

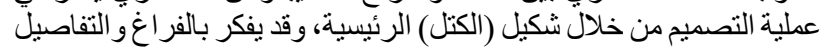

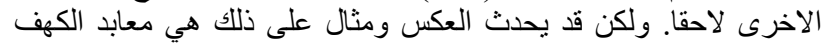

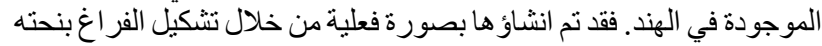

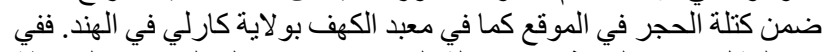

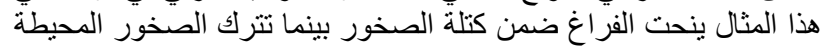

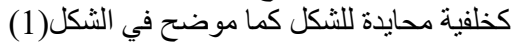

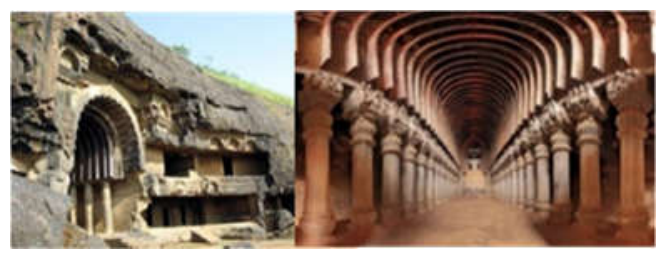

شكل 1: معبد الكهف في كارلي في الهند. تم نحت الفر اغ الداخلي في

الصخور[31] فئ في

العلاقة بين الد/خل والذارج

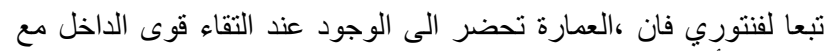

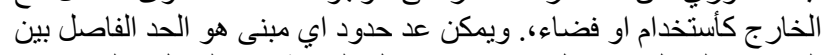

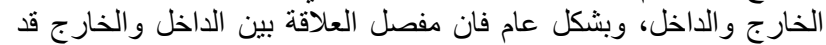

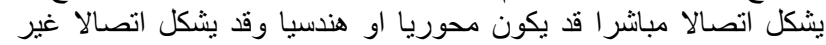

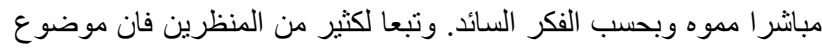




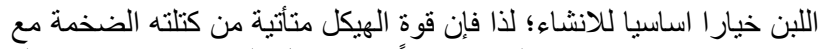

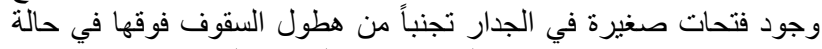

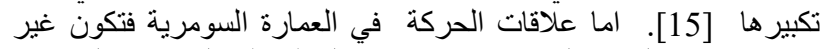

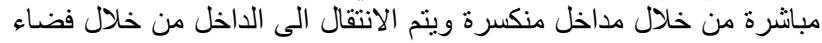

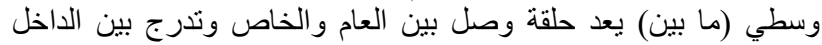

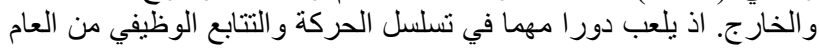

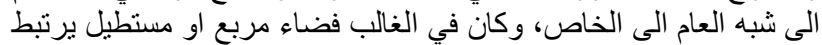

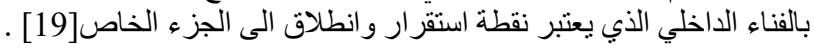

\section{2}

تضم المعابد الاشورية فناءا وسطياو احدا او عدة فناءات تفتح عليها الفضاءات الفاء الفاء

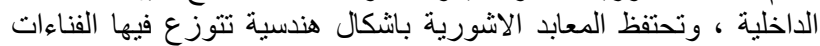

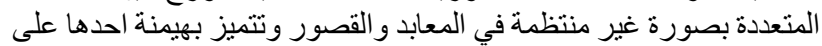

البقية [9].

اما التوجيه في الابنية الاشورية فيكون نحو الداخل مع وجود محاور بصرية

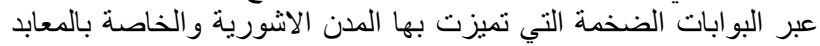

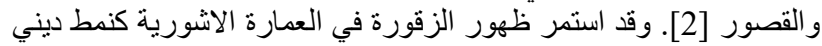

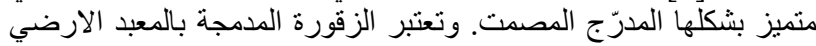

نمطاشكليا مميزا للمعابد الاشورية [7].

اما نظام المنشاو الشكل، فقد شيد الاشوريون هياكل مبانيهه من الحجر و الطين

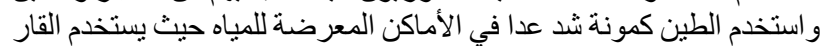

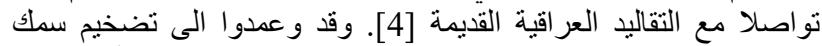

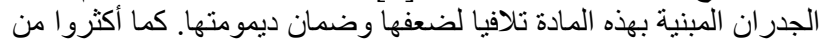

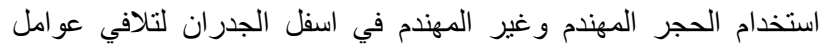

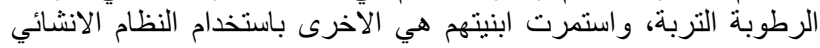

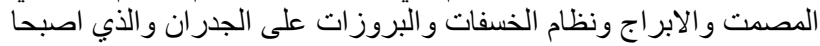

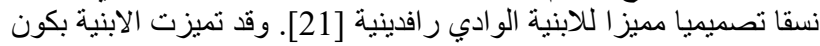

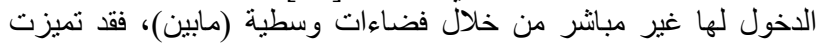
بمداخلها المنكسرة من اجل تحقيق الخصوصنية ولخية والناحية الامنية.

\section{العلاقات الاساسبة في العدارة البابلية}

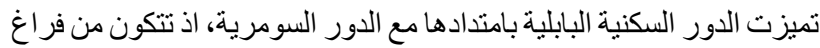

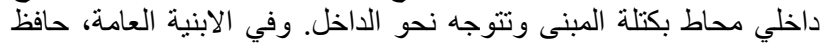

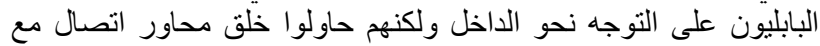

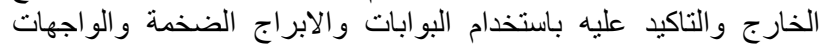

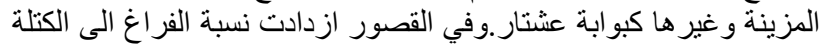

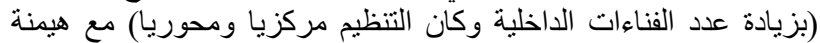

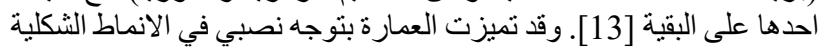

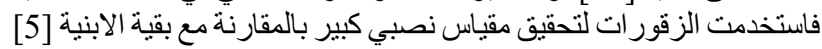

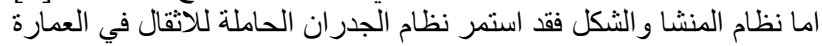

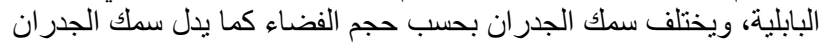

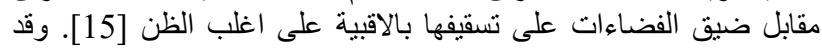

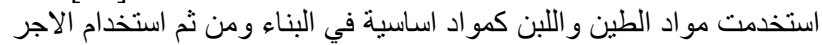

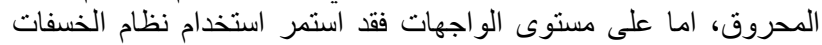

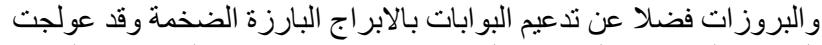

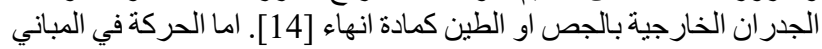

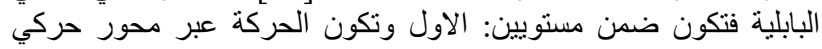

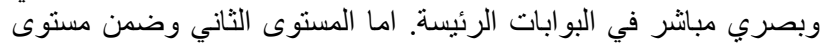

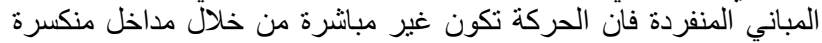

و عبر فضاء وسطي (مابين).

\section{العلاقات الاساسية في مملكة الحضر}

تميزت عمارتها باستخدام مادة الحجر في هياكلها البنائية، وقد ظهرت فئ فكرة الايوان في الحضر كما في الحيرة كفضاء مغلق من ثلاث جهات فئنات ومفتوح
مكونة من عناصر كما في الحروف التي تكون الكلمات. ويصنف لويين العناصر و التي يسميها احيانا مكونات الى فئ

• عناصر فضائية وهي الغرف والساحات والتي تتشكل باحاطنها بعناصر مادية (الاعمدة، الجدران، الفتحات و غير ها ل

• العناصر الاساسية التي تكون الثكل(كالنقطة، الخط، السطح، الجسم [20] • عناصر انشائية (الاعمدة، الجسور، الجدران الحاملة، القباب والاقبية

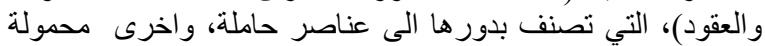

وفيما يتعلق بالهوية المعمارية لكل حضارة، فان خصوصية اي عمارة

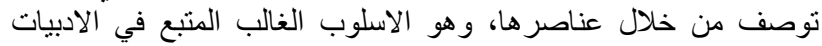
الاثارية وتـاريخ العمـارة الوصفية.

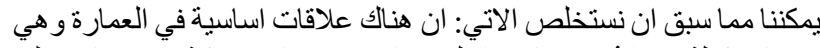

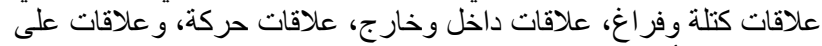

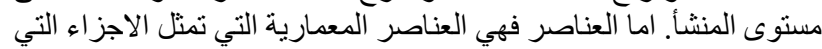

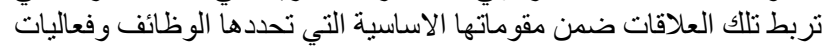

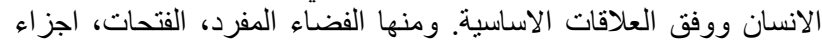

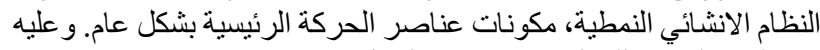
يستخلص البحث تلك العلاقات ضمن النكن الثكل (2):

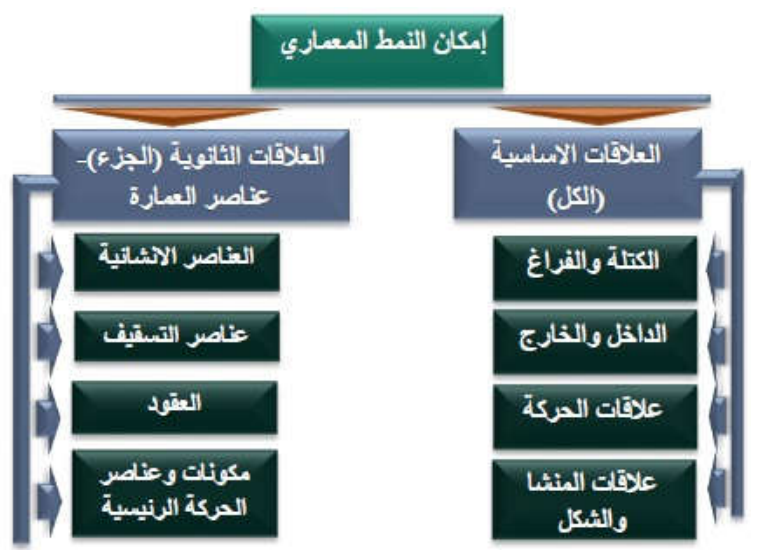

الثكل 2: العلاقات الاساسية والثنانوية في النمط في العمارة (الباحثة)

سيتقصى البحث مؤشرات النمط المعماري وهي العلاقات الاساسية

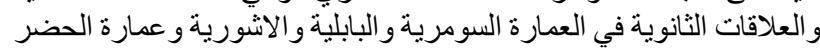

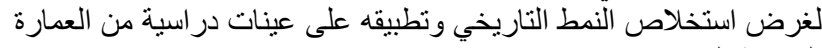

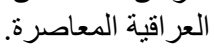

\section{4. العلاقات الاساسية في العمارة الرافدينية العلاقات الاساسبة في العدارة السومرية}

تميزت الابنية السومرية بنمط بنائي ذو خصائص محددة ترتبط بالفضاء الزباء الرئيس والتوجيه، يكون الفضاء الرئيس مربع التئ او مستطيل محاطا بكتلة،

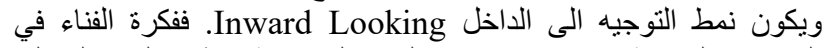

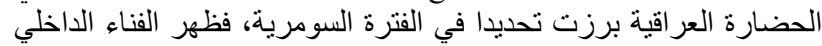

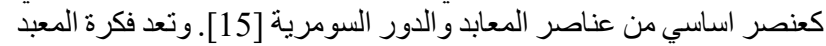

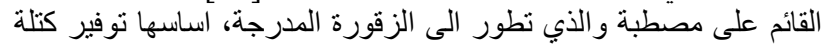

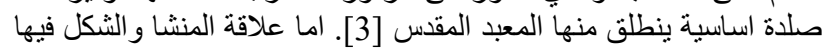

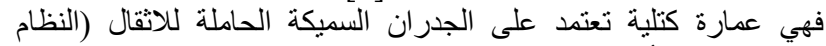

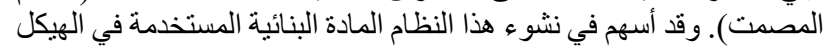

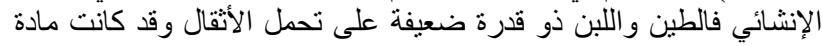




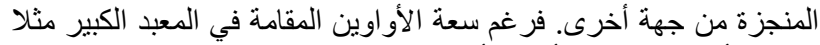

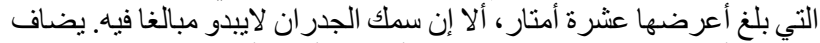

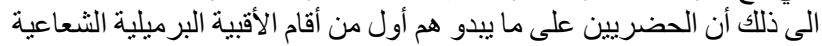

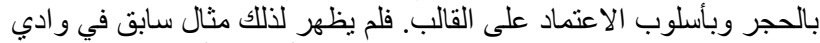

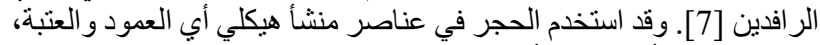

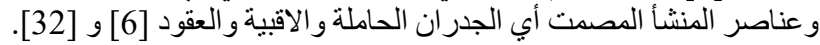

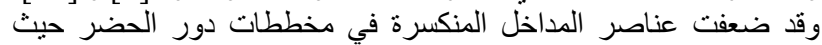

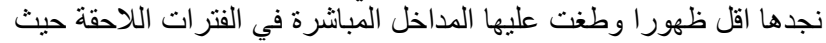

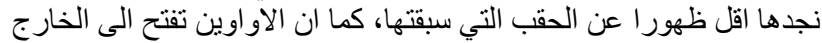
ويكون الدخول اليها مباشرة [12].

وعليه ومن خلال الطرح السابق يستخلص البحث العلاقات الاساسية في

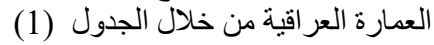

بالكامل من الجهة الرابعة. وقد ظهرت المعابد ذات التشكيل الثناثي، ودخل التهل

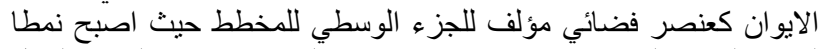

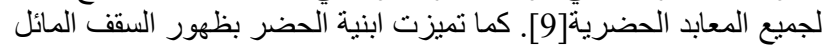
pitched roof

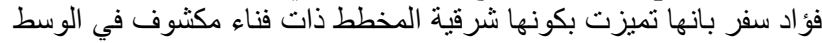

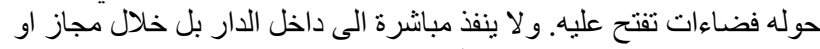

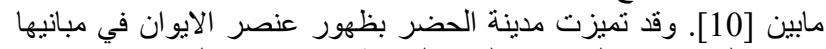

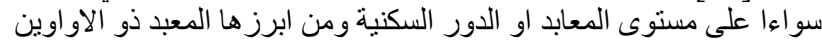

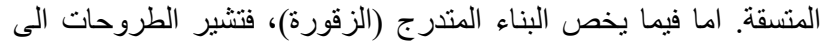

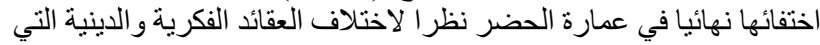

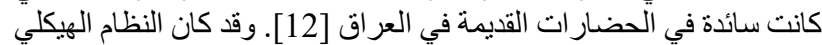

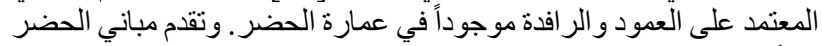

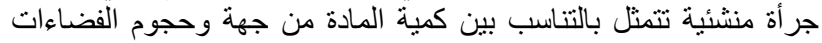

جدول 1: علاقات الكتلة والفراغ، التوجه في العمارة العر اقية عبر التاريخـ اعداد الباحثة

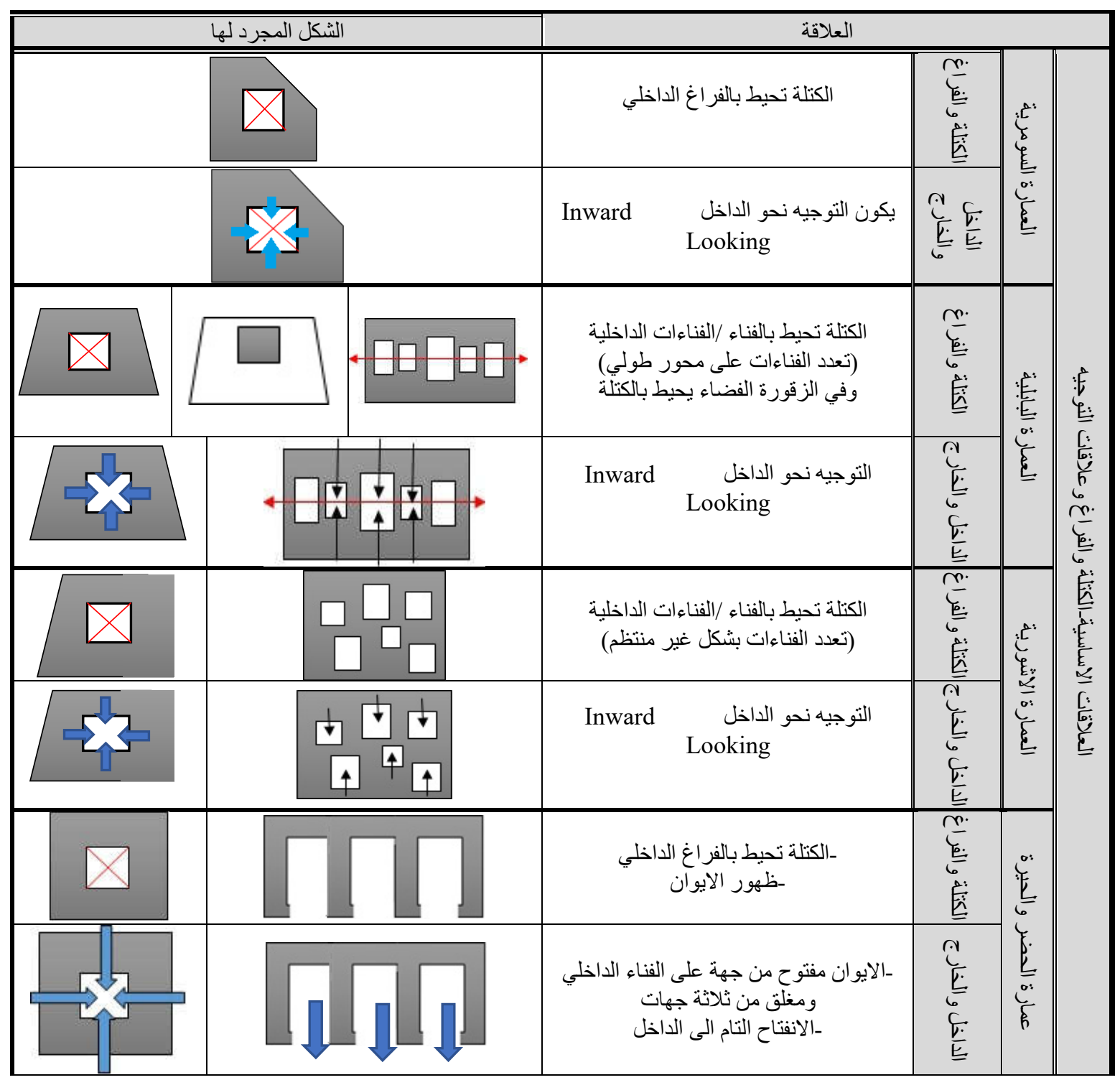




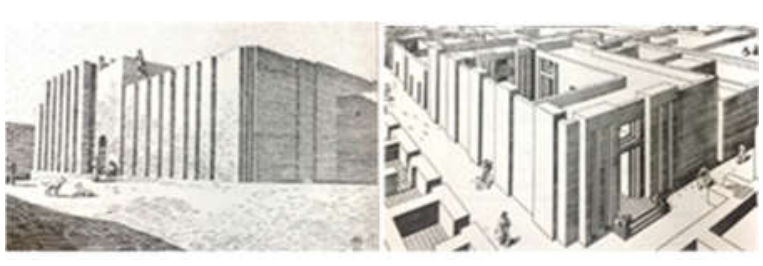

الثكل 4: عنصر الركن في العمارة العر اقية. اليمين معبد خاني في تل

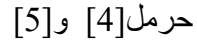

\section{العدود في العمارة العراقية}

يعد النظام المصمت، هو النظام الانشائي السائد العمارة العر اقية القديمة

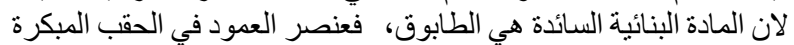

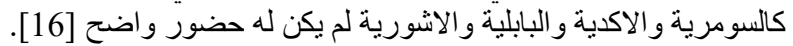

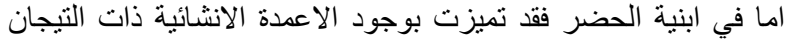

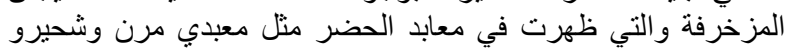

\section{6}

تتميز المباني العر اقية التاريخية في جميع العصور ، بالتاكيد على اتجاهية

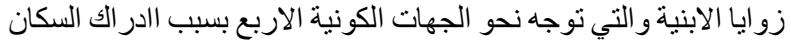

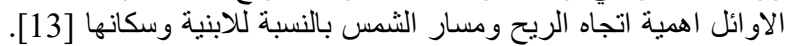

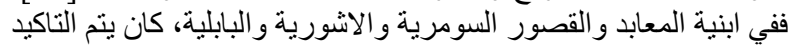

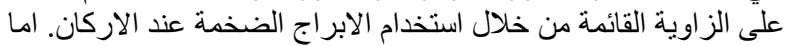

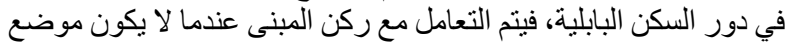

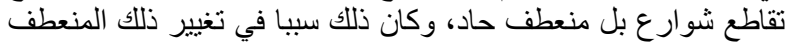

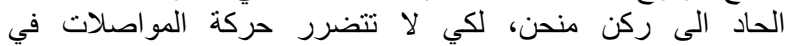

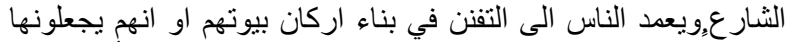

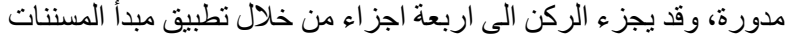

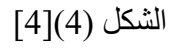

\section{الملقف الهوائسي (البادكبي) في العمارة العراقية}

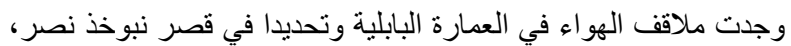

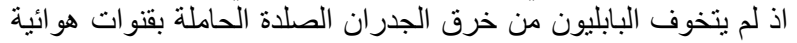

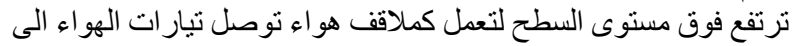

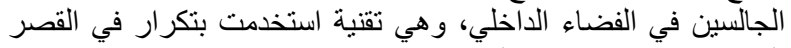

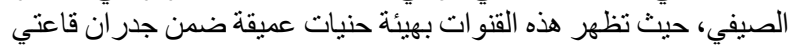

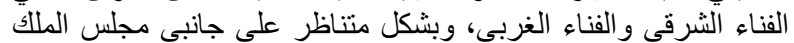

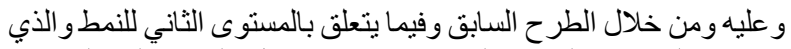

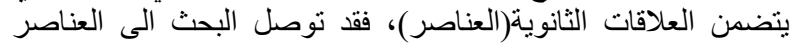

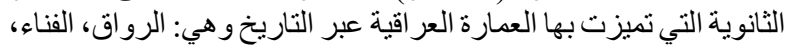

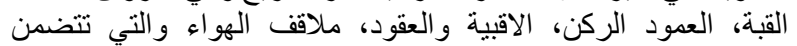

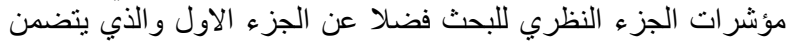

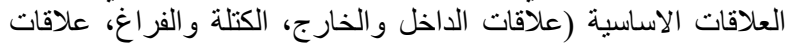

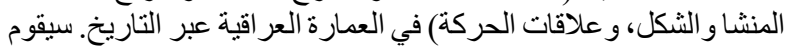

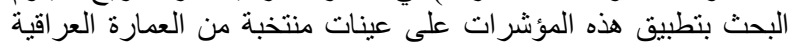

المعاصرة ضمن الجزء العملي لهذا البحث عذئ.

\section{8}

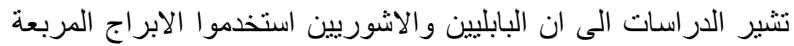

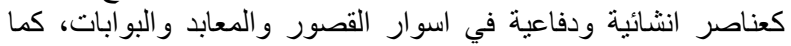
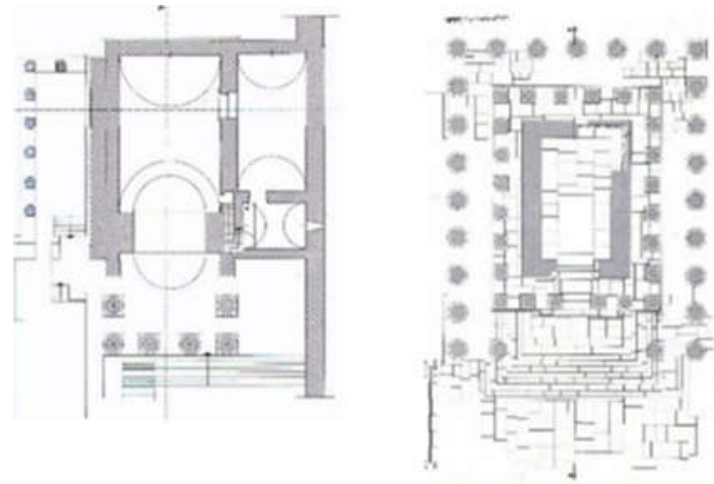

الثكل 3: الرواق في ابنية الحضر . اليمين معبد مرن، اليسار معبد شحيرو. [10] الخطن

\section{العلاقات الثانوية_ العناصر في العمارة العراقية}

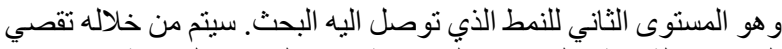

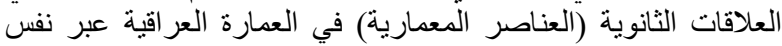

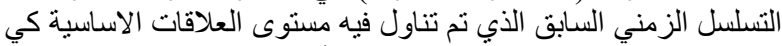

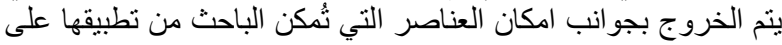

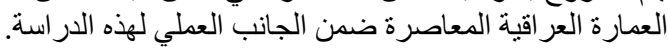

$$
\text { الرواق في العمارة العراقية }
$$

يضم البيت السو مري تحديدا وحسب الباحث الانكليزي (وولي) شرفة تتقدم

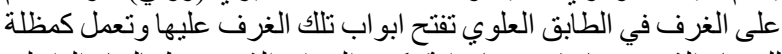

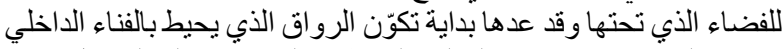

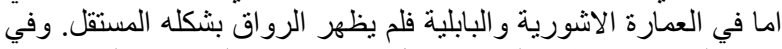

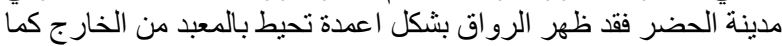

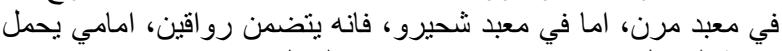

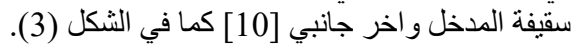

$$
\text { عنصر (لفناء }
$$

وقد تمت الاشارة اليه ضمن علاقة الكتلة بالفر اغ و علاقة الداخل والخارج.

$$
\text { القبة في الععارة العراقية }
$$

ظهرت القبة وبحسب دراسة (السر وولي) ضمن المعابد السومرية في

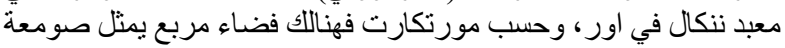

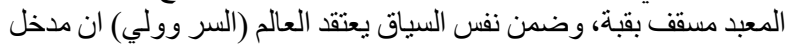

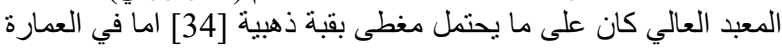

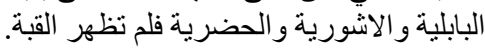

$$
\text { العقود والاقبية في العدارة العراقية }
$$

تثير الطروحات الى ان اولى الاقبية و العقود في العمارة العر اقية القديمة

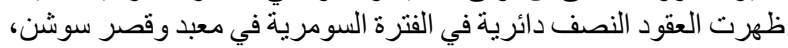

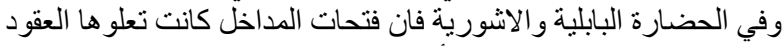

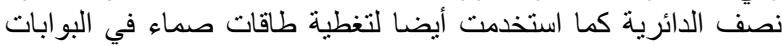

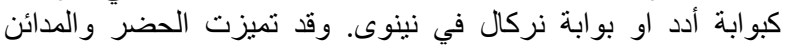

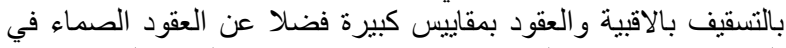

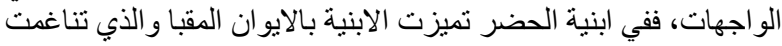

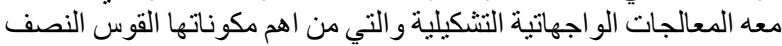

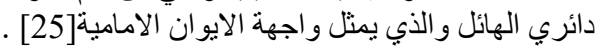




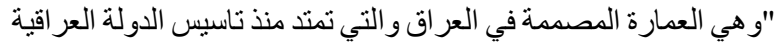

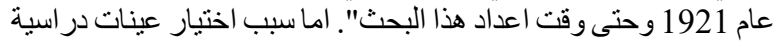

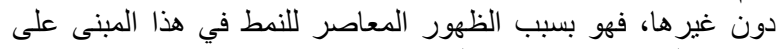
مستوى العلاقات الاساسية و الثانوية.

\section{1}

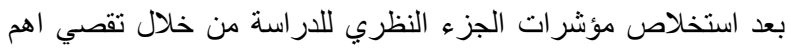

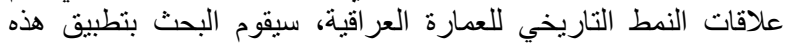

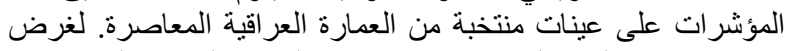
تقصي استخدام النمط التاريخي وتغير اته في العمارة العر اقية المعاصرة العرة لعرة

6.1 .1

المستنصرية
تميزت العمارة السومرية باستخدام الابراج المربعة او المسنطيلة

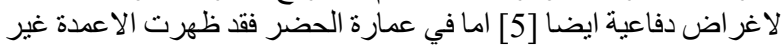

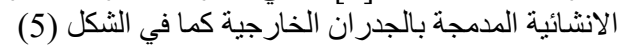

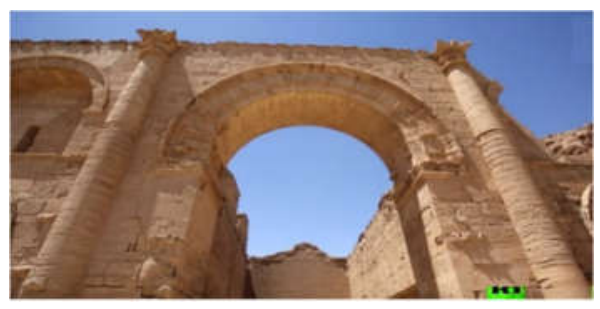

الشكل 5: الاعمدة المندمجة في ابنية الحضر [35]

التطبيق العملي

سيقوم البحث بتطبيق المؤشرات المستخلصة للعلاقات الاساسية

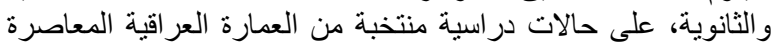

جدول 2: علاقة الكتلة بالفر اغـ الفناء الداخلي في الجامعة المستنصرية_ اعداد الباحثة

\begin{tabular}{|c|c|}
\hline \multicolumn{2}{|c|}{ الكتلة و الفراغ في مجمع الجامعة المستنصرية } \\
\hline بط بالفر اغ ـالعلاقة الى الداخل و الخارج & \\
\hline 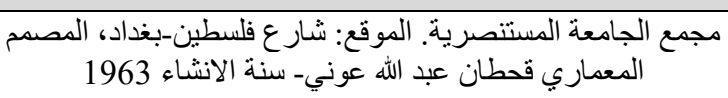 & الاحاطة النسبية للفرأ| \\
\hline
\end{tabular}

تغير في احاطة الكتلة و الفر اغوتكر ار الفر اغات والكتل، الاحاطة من ثلاث جهات اما الجهة الرابعة فبعنصر حركي عمودي
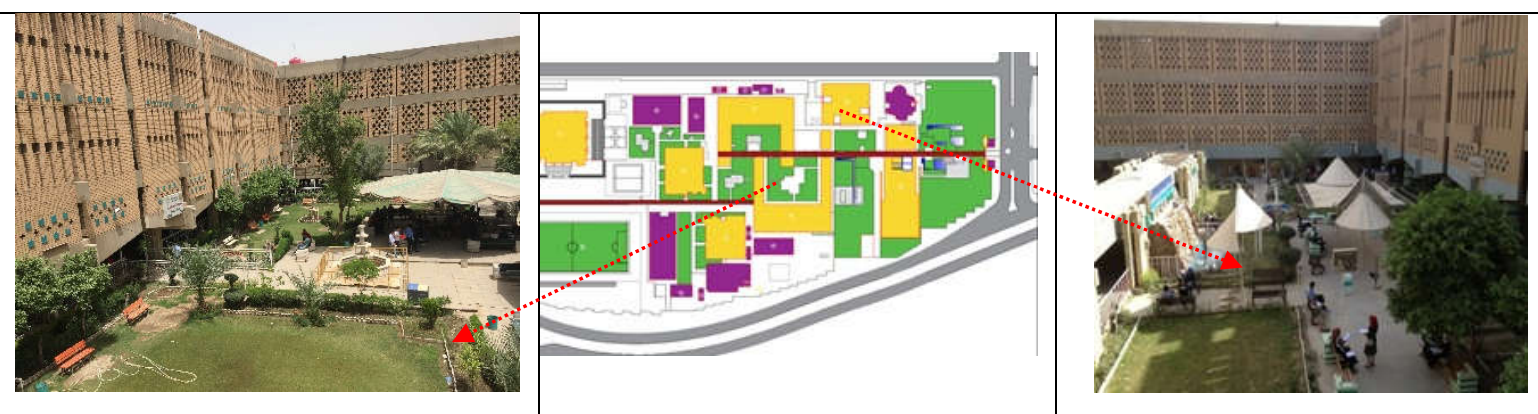

* تغير في احاطة الكتلة و الفر اغ مع تكرار الفر اغات

علاقات الحركة

6.1 .2

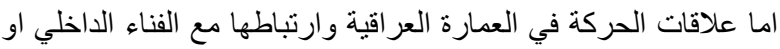

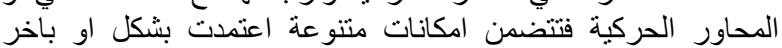
بعلاقتها مع الفناء الوسطي لمعي 
جدول 3: علاقة الكتلة بالفر اغـ الحركة حول الفناء في مبنى الامانةـ اعداد الباحثة

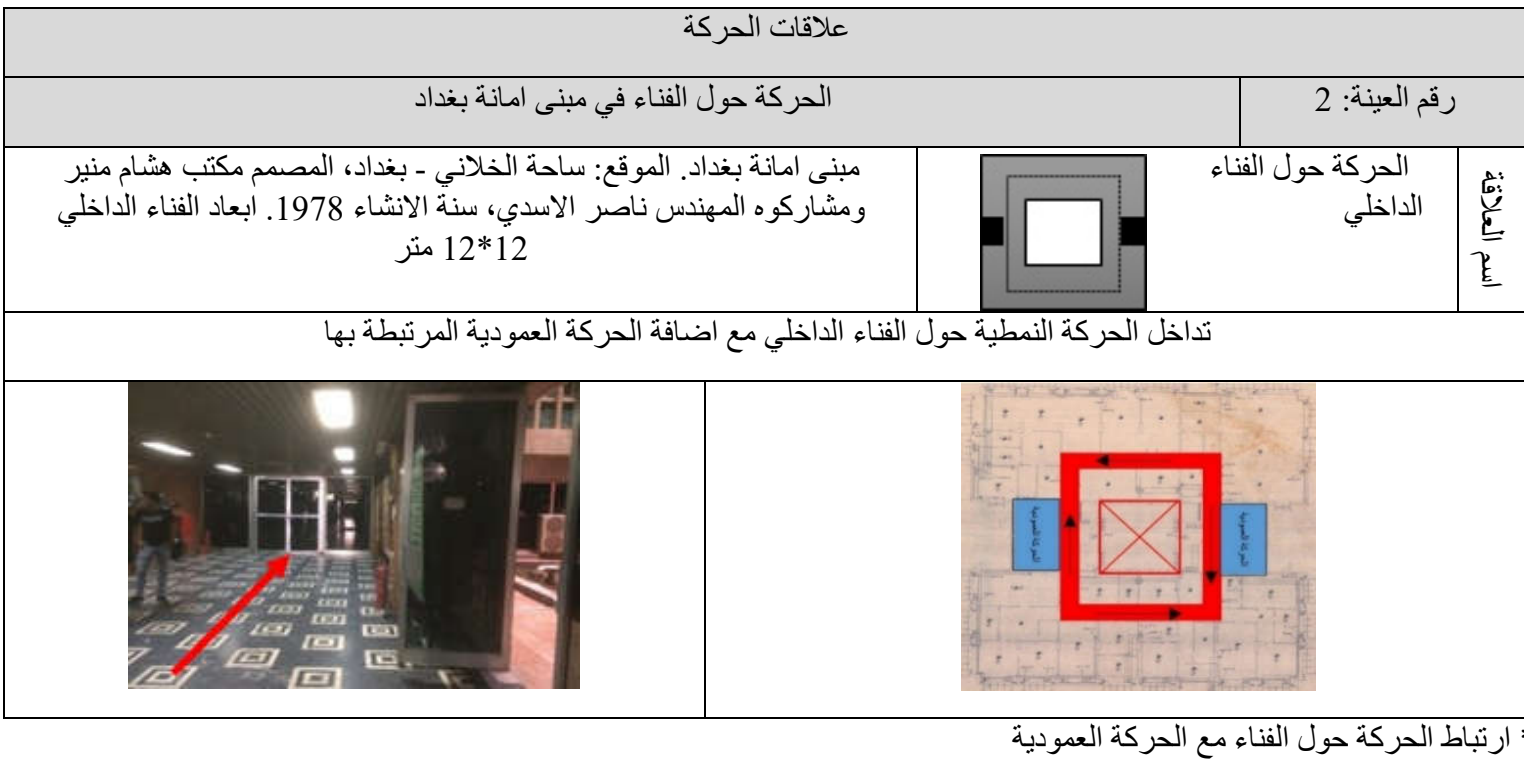

6.1 .3 علاقات المنشا والثكل- الشكل والمنشا في مشروع مبنى البرلمان العراقي

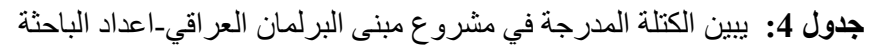

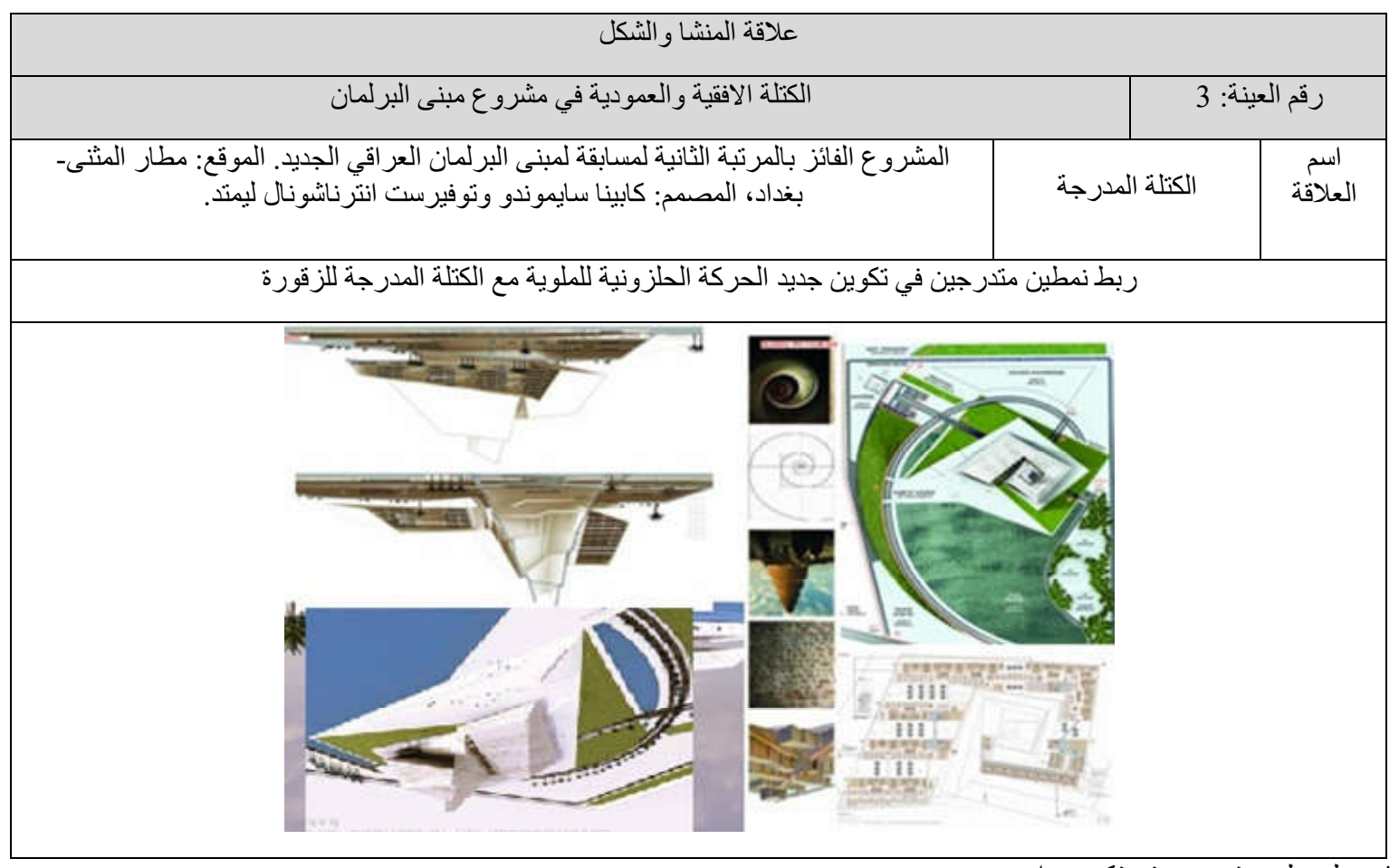

* ربط نمطين متدرجين في تكوين و احد

تناولها من خلال تطبيقها على حالات در اسية منتخبة من العمارة العر اقية

المعاصرة.
وهو المستوى الثاني الذي توصل له البحث ضمن مؤشرات الإطار

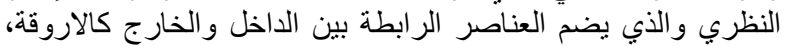
الفناء الداخلي بوصفه عنصر الا، القباب، الاقبية، الايوان، العقود. وسيتم 
النمط الجزئي- عنصر الرواق في مبنى جامعة الكوفة

جدول 5: يبين عنصر الروفة جئة في جامعة الكوفةـ اعداد الباحثة

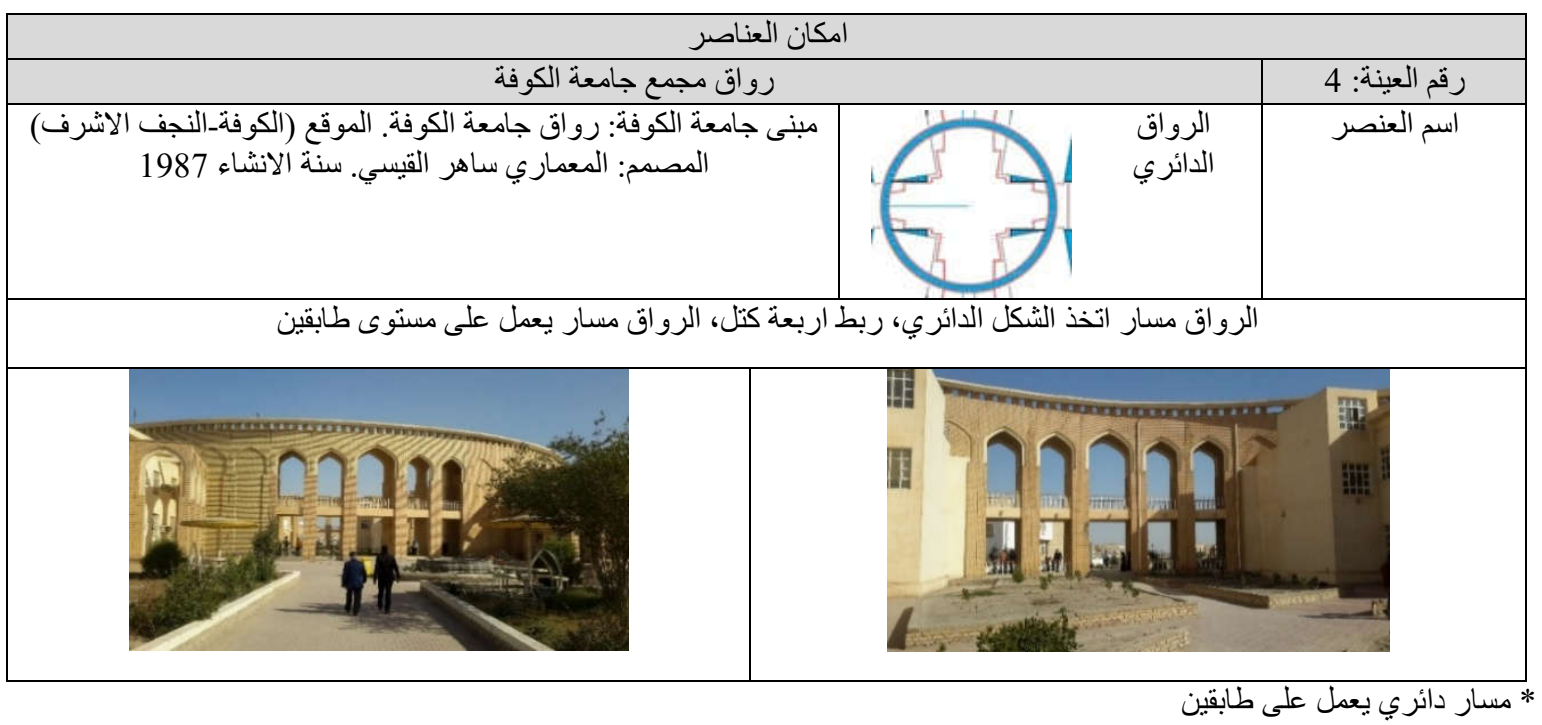

النمط الجزئي- عنصر الفناء في دار معاذ الالوسي

6.2 .2

جلول 6: عنصر الفناء في دار معاذ الالوسي_ اعداد الباحثة

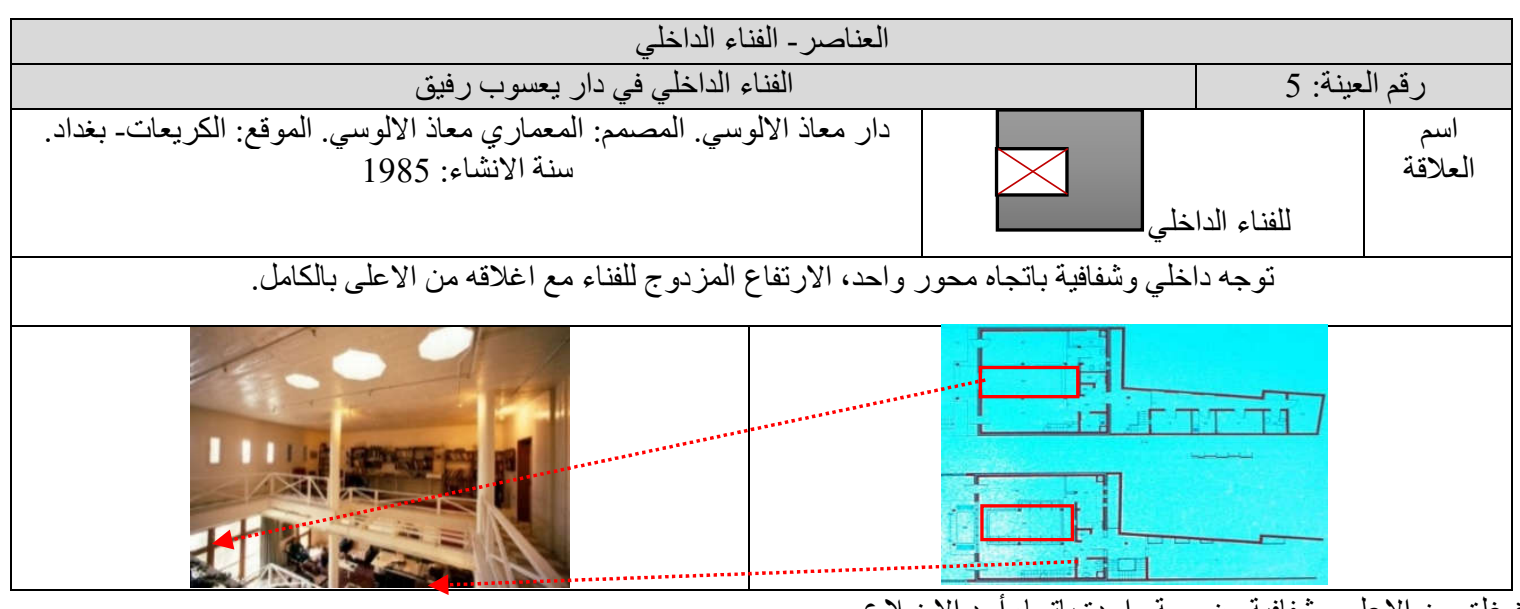

* غلق من الاعلى وشفافية من جهة واحدة باتجاه أحد الاضلاع

6.2 .3

جدول 7: يبين عنصر القبة في مبنى نصب الثهيد- اعداد الباحثة

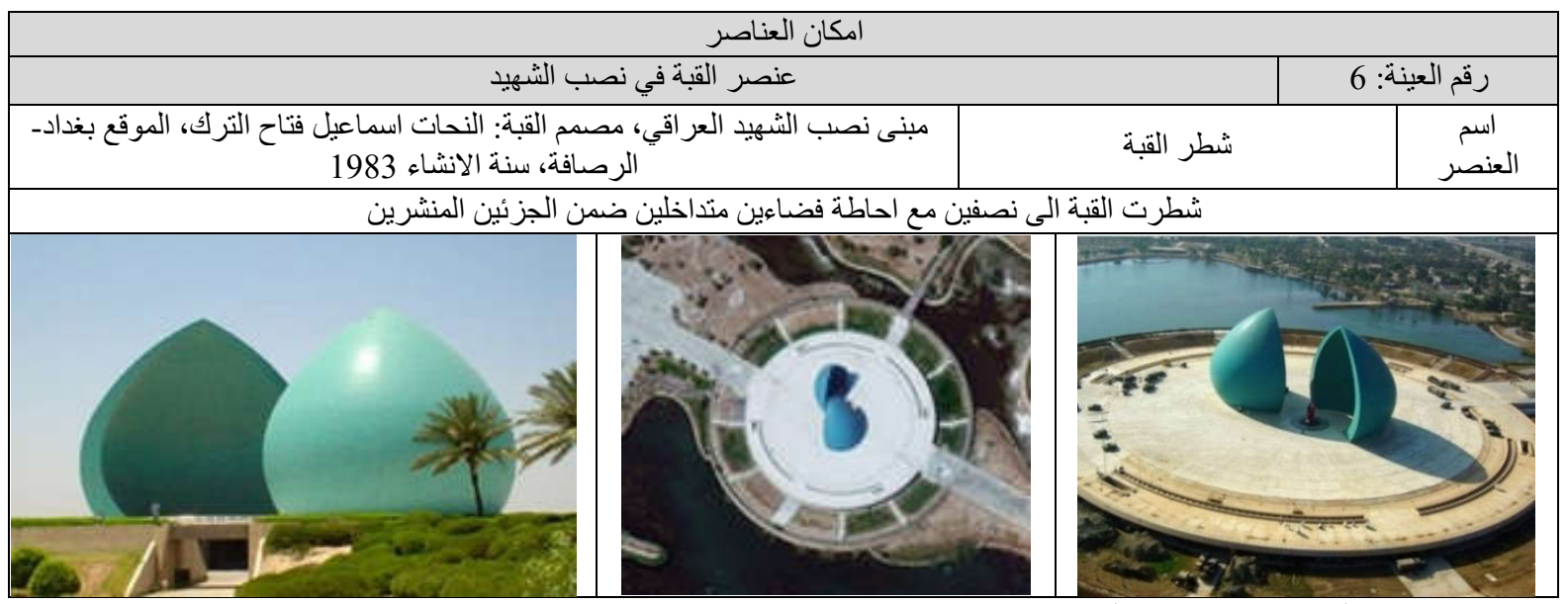

* تنويع في الاحاطة الفضائية بسبب شطر القبة 
جدول 8: يبين القوس النصف دائرية في مبنى اتحاد الصناعات العر اقيةـ اعداد الباحثة

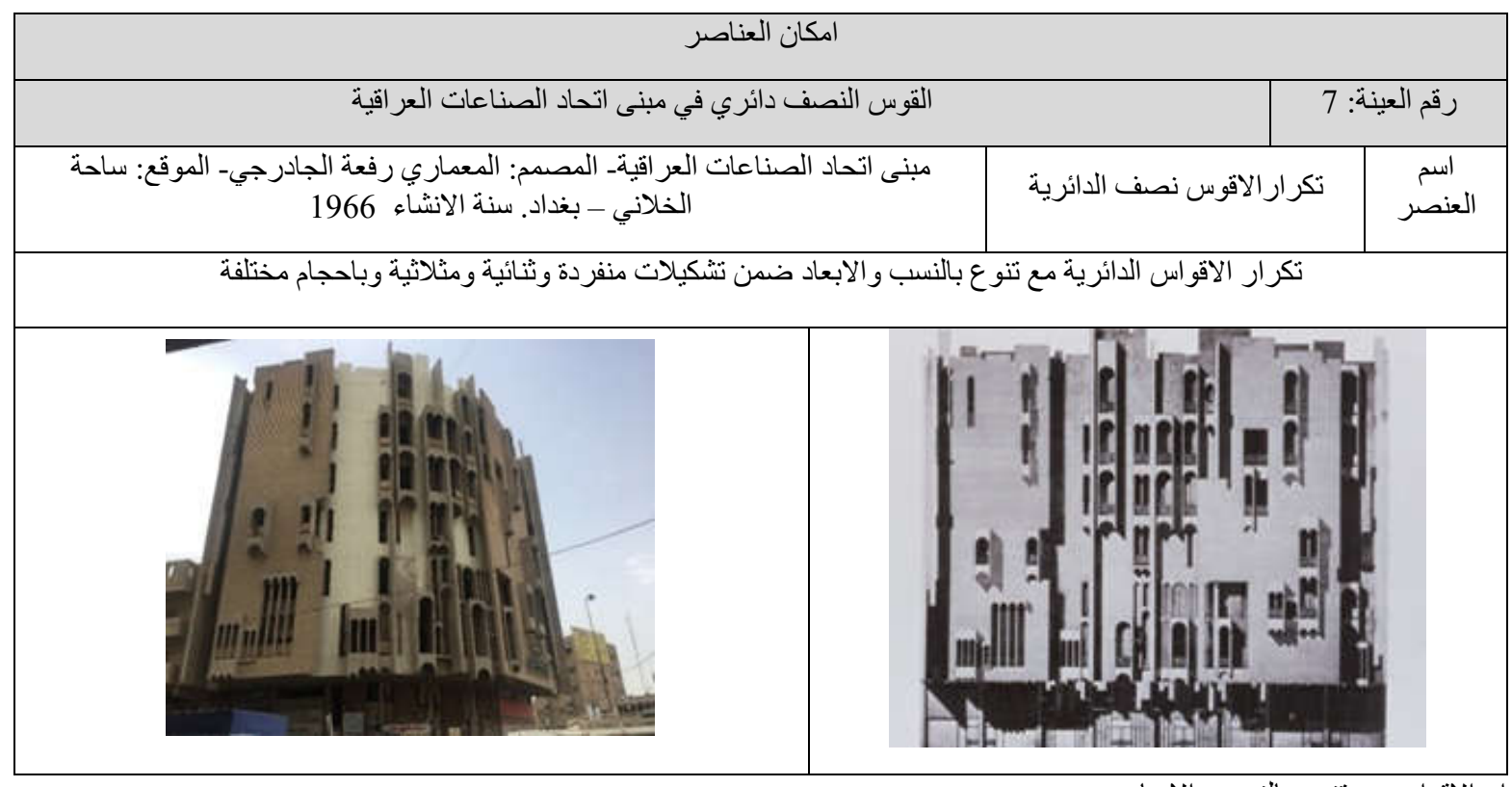

* تكر ار الاقو اس مع تنوع بالنسب و الابعاد

6.2.5 النمط الجزئي- عناصر الابراج النصف دائرية في مبنى قصر المؤتمرات

جدول 9: يبين الابر اج النصف دائرية في مبنى قصر المؤتمراتــاعداد الباحثة

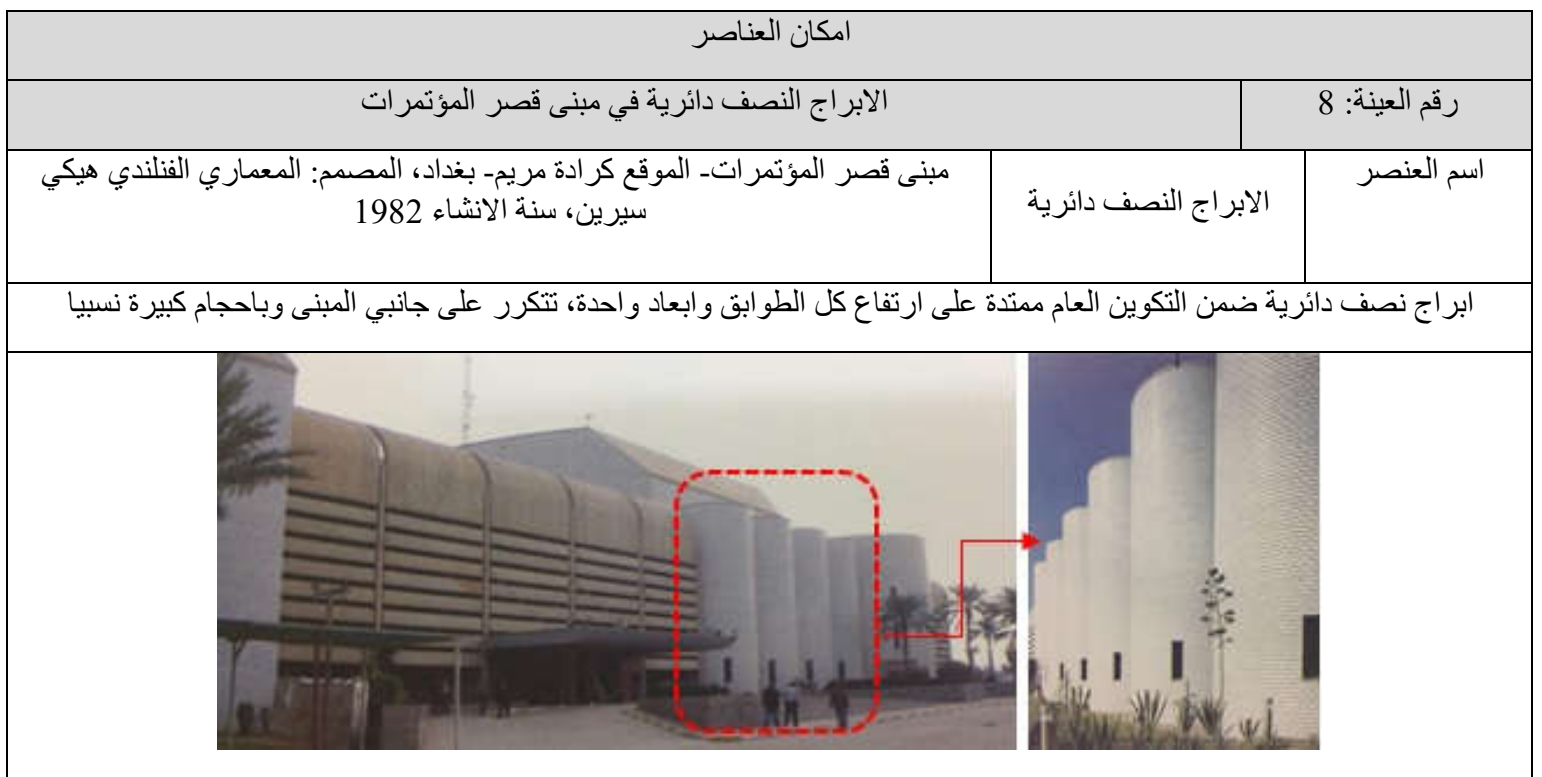


6.2 .6 النمط الجزئي- عنصر المدخل في مبنى المتحف الزراعي جدول 10: بين المدخل في مبنى المتحف الزر اعي_ اعداد الباحثة

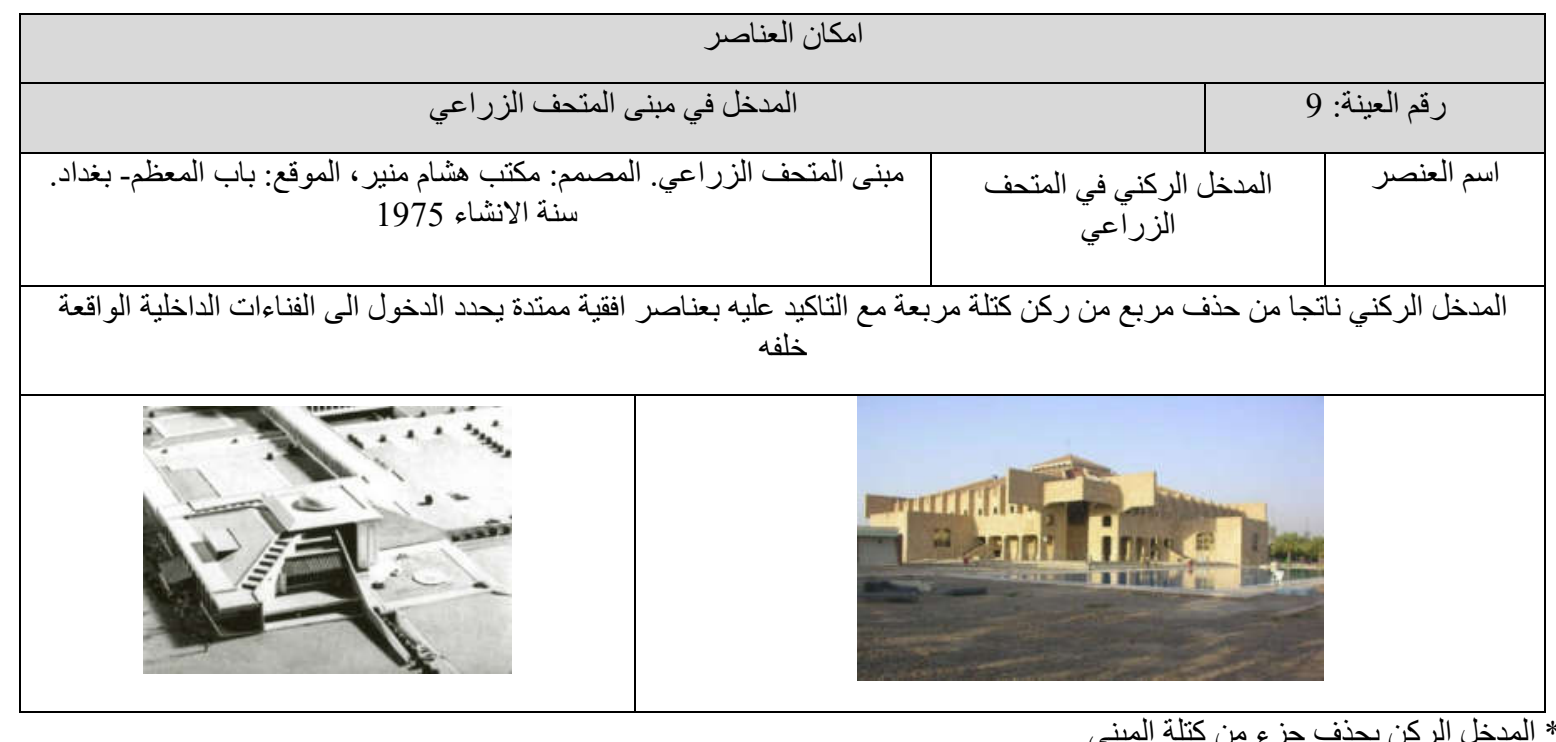

6.2.7 النمط الجزئي - عنصر الركن بناية كلية القانون جامعة كربلاء

جدول 11: يبين عنصر الركن في كلية القانون جامعة كربلاء_ اعداد الباحثة

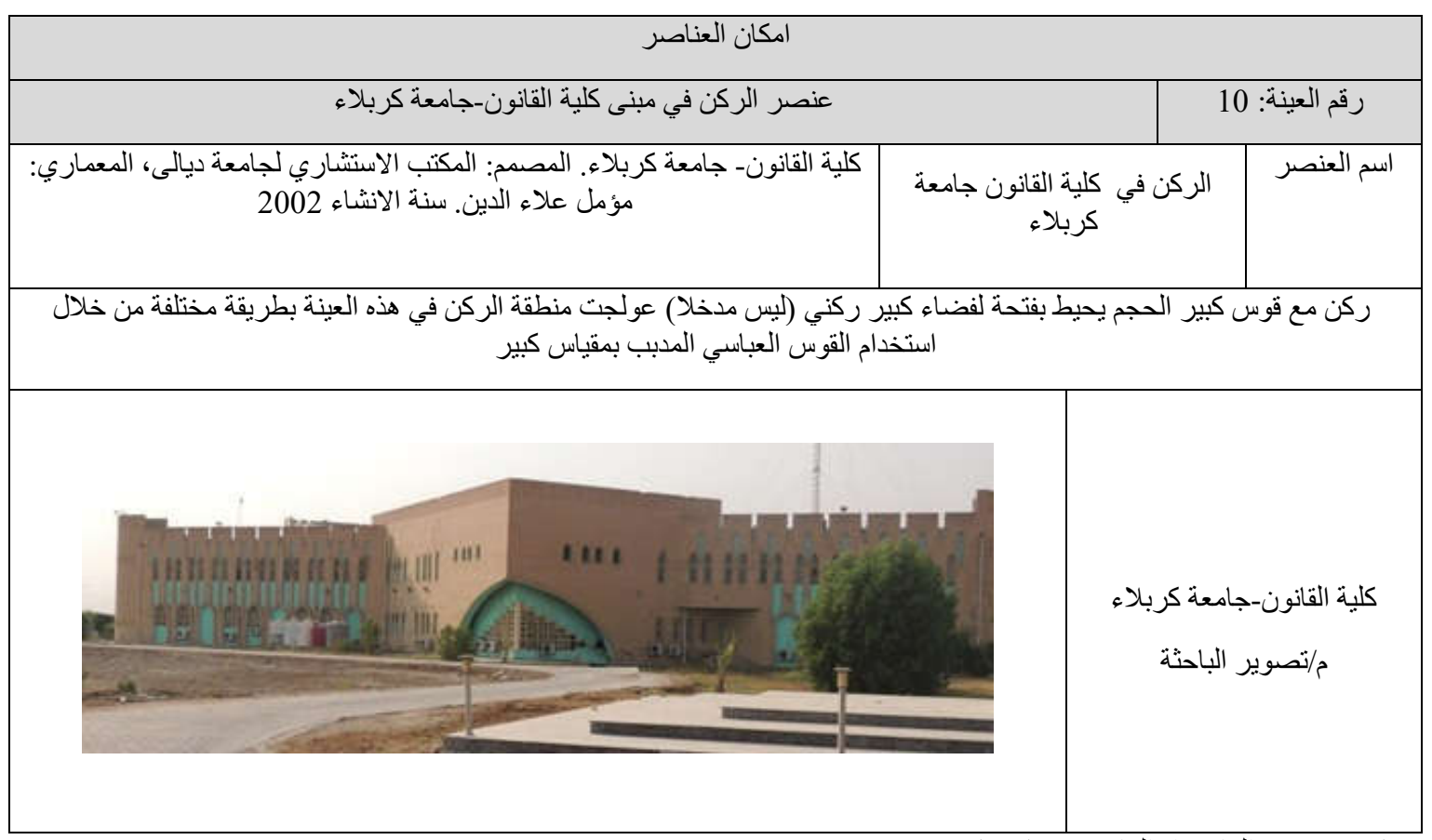


النمط الجزئي-النظام البيئي المنفعل (البادكير)

جدول 12: يبين عنصر البادكير في مبنى دار الازياء العر اقيةـ اعداد الباحثة

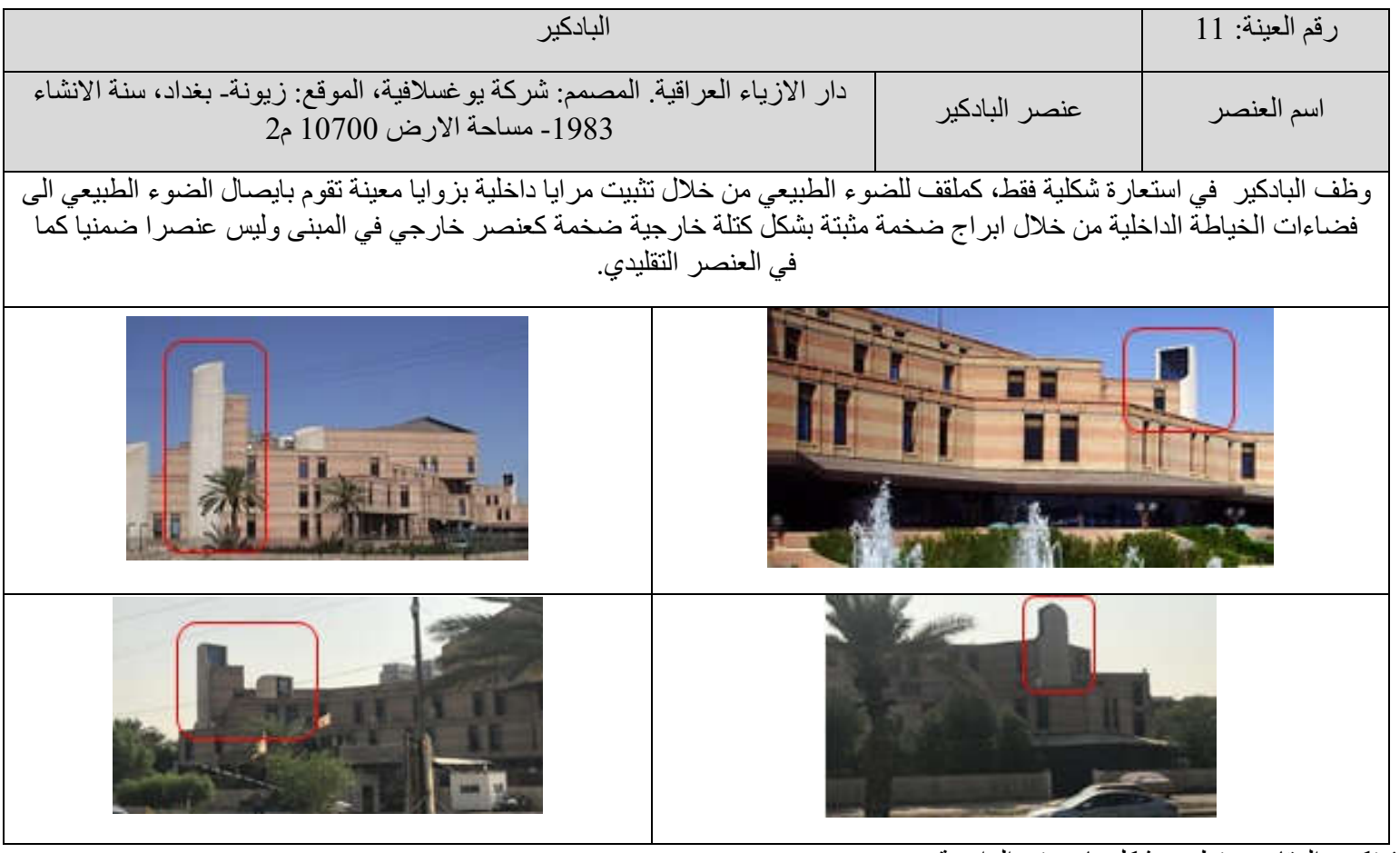

* تكبير المقايس وتظهر بشكل بارز في الواجهة

جدول 13: تحليل العينات الخاصة بالعلاقات الاساسية_ اعداد الباحثة

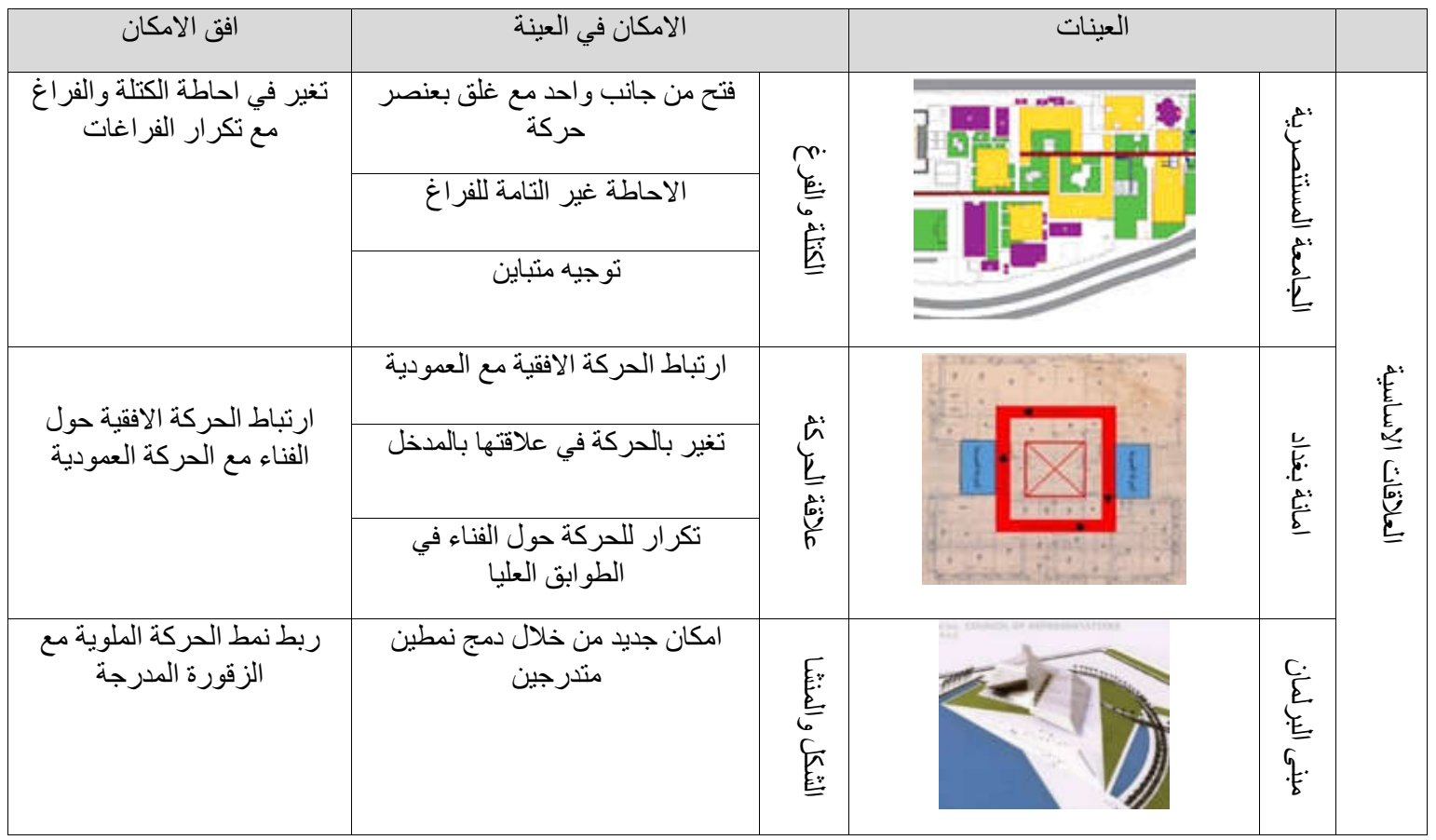


جدول 14: تحليل العينات الخاصة بالعلاقات الثانوية_ اعداد الباحثة

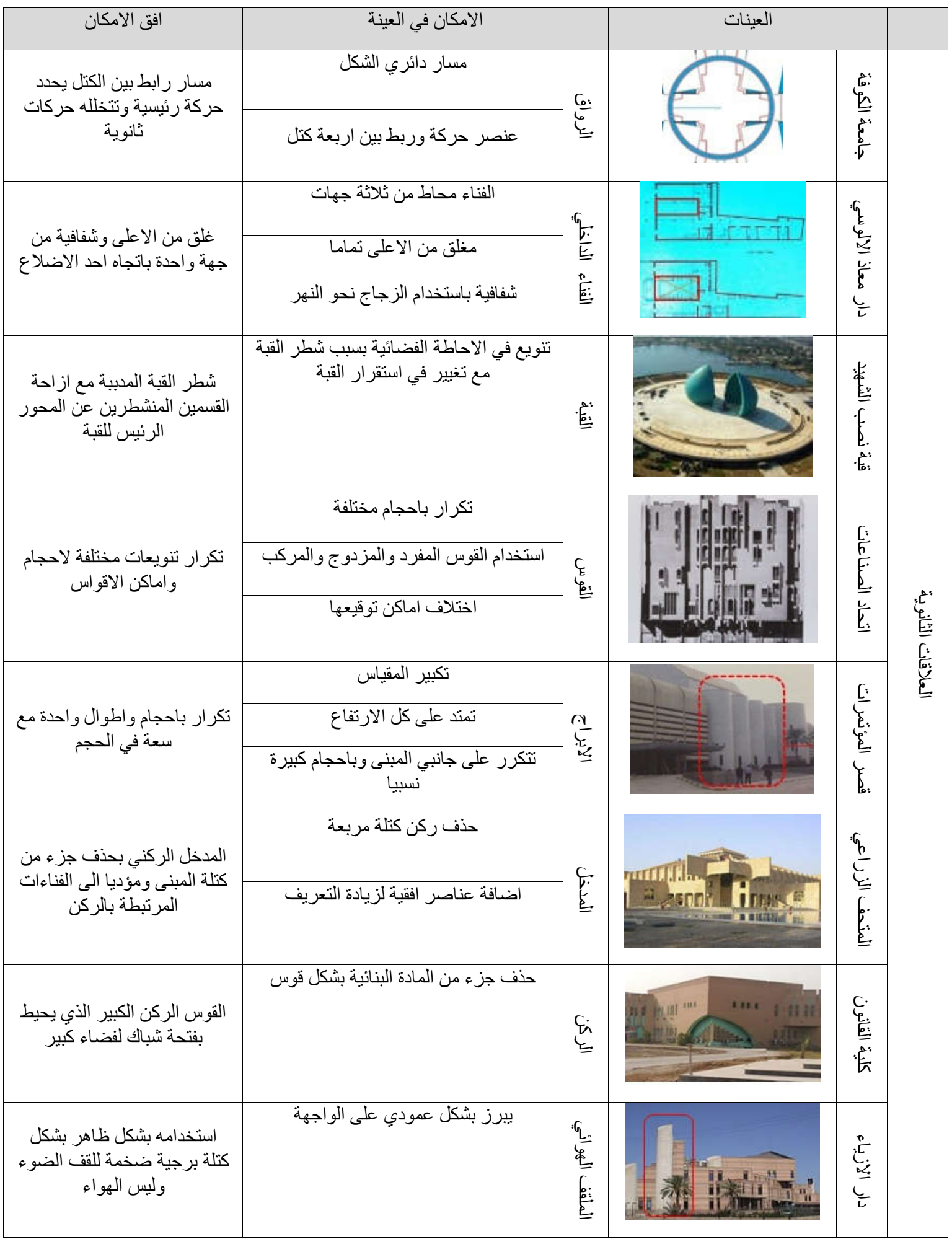


جنان عبد الوهاب، ،"جدلية التواصل في العمارة العراقية"، دار

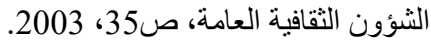

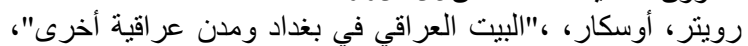

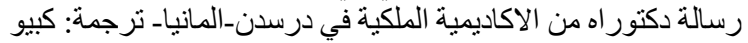

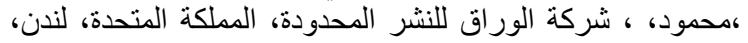

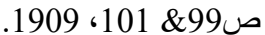

شريف يوسف، تاريخ العمارة العراقية في مختلف العصور،

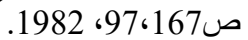

الثمس، ماجد عبد الله ،"الحضر -العاصمة العربية"، وزارة التعليم

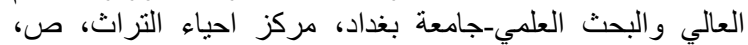
1988،580

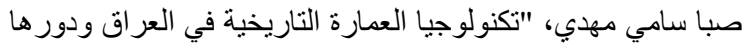

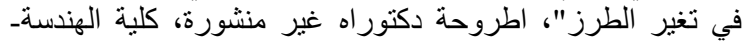

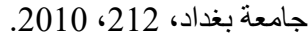

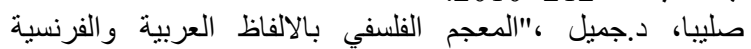
و اللاتينية"، الجزء الاول، دار الكتاب العالمي، لبنان-بيروت، لصن، 1994،507

العامري، شذى عباس، "التواصل في عمارة الفضاء الرافديني"،

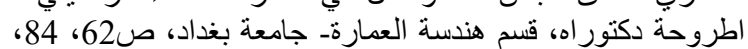
. 2010 ، 150

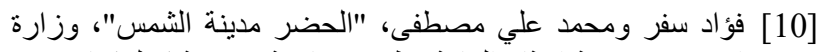

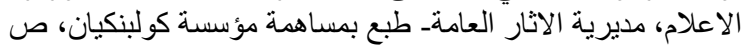

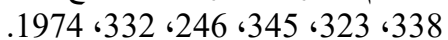

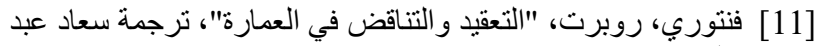

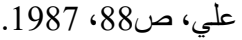

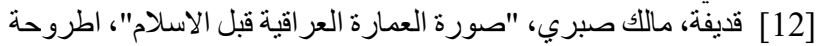

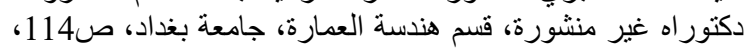
2006 ، 91

لو لويد، سيتون، "آثار بلاد الر افدين"، ترجمة سامي سعيد الأحمد، دار

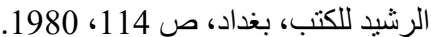

[14] لويد، سيتون، "آثنار بلاد الر افدين"، 172، ترجمة محمد طلب، مطبعة الثشام-

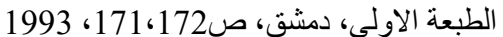

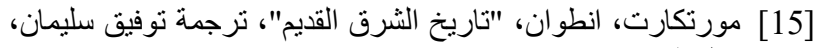

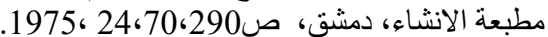

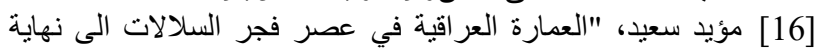

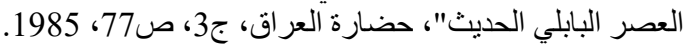

\section{Refrences}

[17] Alexander, Christopher, “A Pattern Language, Center for environmental structure," California, P. VXIII, 1977.

[18] Argan, Giulio Carlo, "On The Typology of Architecture (1963), published in, Theorizing A New Agenda For Architecture: An Anthology of Architectural Theory", 1965-1995, Kate Nesbitt, Princeton Architectural Press, New York, pp.242246 \& 242-246, 1996.

[19] Badawy, Alexander, "Architecture in Ancient Egypt \& the Near East”, p.102, 1966.

[20] Ching, Francis, "Architecture, Form, Space and Order", 4th edition, published by John Wiley \& Sons, Inc., Hoboken, New Jersey, p.1, 2015.

[21] Drioton, Etienne, "The Rivalry and Achievements of the Empires", in, Larousse Encyclopedia of Prehistoric and ancient art, p.148, 1981.

[22] Frankl, Paul, "Principle Architectural History- The four Phases of Architectural Style", 1420-1900, p.187, 1968.
7. الاستنتاجات

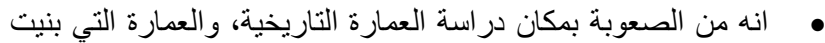

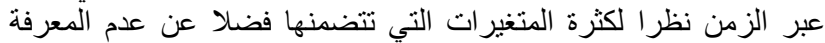

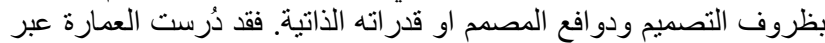

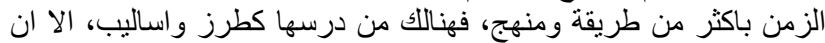

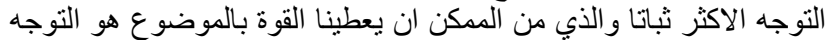

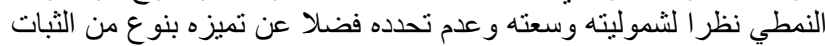
و الذي من خلاله من الممكن ان نتعرف ولن على القوة في العمارة.

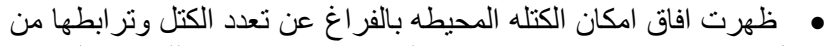

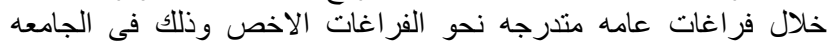

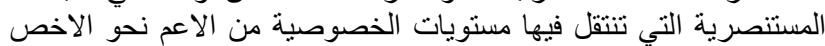

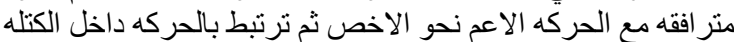

• ان العلاقات الاساسيه ستبقى متفاعلة مع كل التطورات في العمارة

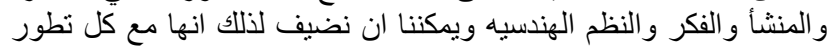

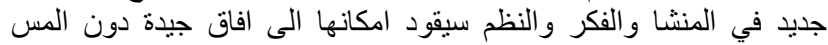
بجو هر ها.

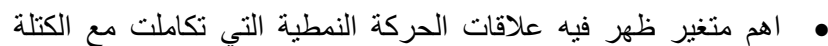

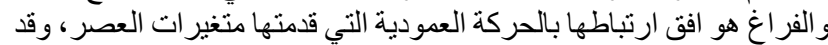

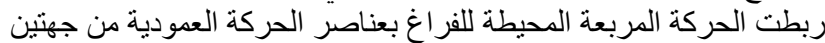

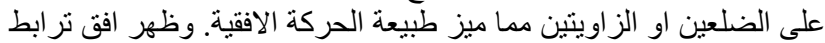

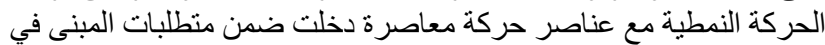

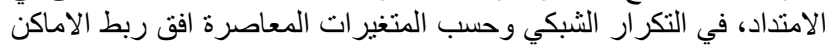

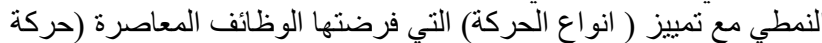
زوار - حركه مستخدمين ، حركة خدمات).

• ان شطر العنصر قبة نصب الثهيد يمتلك امكانيات غير محدودة وان هناك امكانات كثيرة يمكن ان بر اها المصمم في شكل العنصر وحسب الئب رؤيه الذات

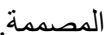

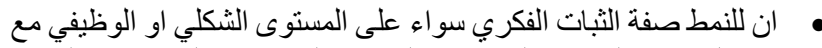

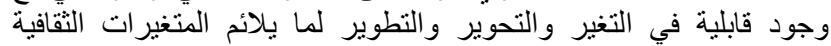

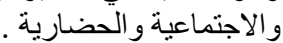

• ان النمط قادر على التو اصل المعاصر، وذللك بسبب تفهم النمطية للعمارة

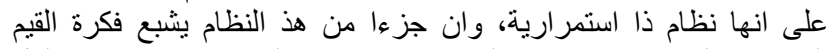

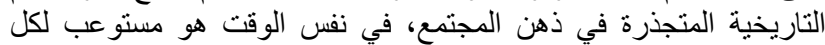

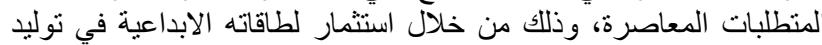

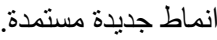

• استمر النمط المصمت الكتلي في العمارة العر اقيه المعاصرة نمطا سائدا

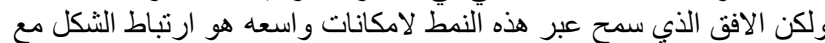

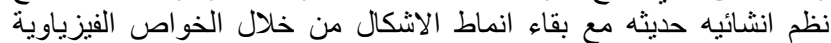

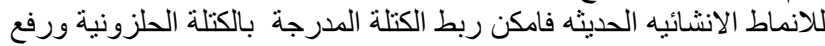

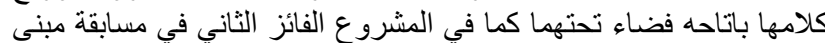

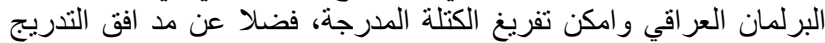

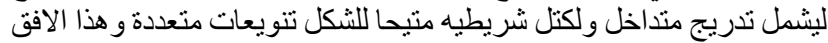

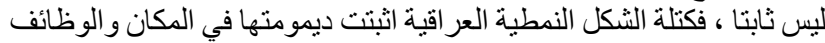

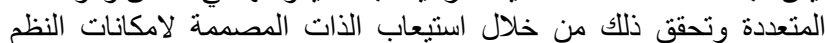

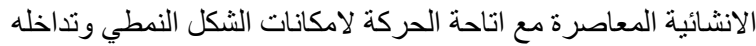

\section{المصادر}

الامام، محمد وليد، "تحولات الثكل المعماري؛ تجوال الثكل

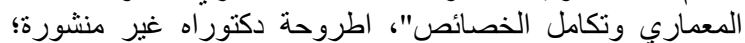

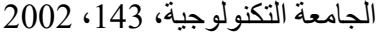

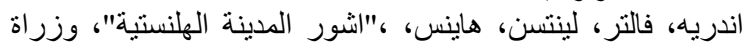

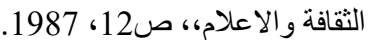


[30] Noble, Jonathan, "The Architectural Typology", Antoine Chrysostome Quatremere De Quincy (17551849)

[31] Rasmussen, Steen Eiler, "Experiencing Architecture", MIT Press; twenty eight edition edition, p.15, 21, 2000.

[32] Reuther,Oscar, "Parthian Architecture: a History, in A Survey of Prsian Art", ed. Arthure Pope, Vol.1, Oxford University Press, U.K.1967, p.425.

[33] Sekler, Eduard F., "Structure, C'onstruction, Tectonics structure in Art and in Science", Edited by, Georgy Kepes, Studio Vista, London, p.120, 1965.

[34] Woolley, Charles Leonard, "The Sumerians", W. W. Norton \& Company, p.12\&145, 1965.

[35] https://www.rewity.com/forum/t354407.html

[36] http://www.arch.mcgill.ca/prof/sijpkes/arch-struct2008/book-2.pdf
[23] Krier, Rob, "Element of Architecture,, In Architectural Design", Edited by: Andreas C Papadakis,Academy Editions, London, p.26, 1983.

[24] Leupen, Bernard et al, "Design and Analysis", Van Nostrand Rinhold,NewYork, p.24, 1997.

[25] Lioyd, Seton \& Muller Martin, "Ancient Architecture Mesopotamia, Egypt, Crete, Greece", Harry N. Abrams:, 1st US edition, p.78, 1974.

[26] Macdonald, Angus, "structural design for Architecture", Architectural Press, Oxford, p.2, 1998.

[27] Michael Pidwirny \& Scott Jones, University of British Columbia Okanagan,2nd edition , p.23, 2010.

[28] Nervi, P.L, "Aesthetic and Technology In Building", Edition by Fischer R.E, McGraw Hill Inc., New York, p.67, 1966.

[29] Nesbitt , Kate, "Typology and Transformation, , in Theorizing A new Agenda for Architecture", New York , p.243, \&244, 1996.

\title{
The use of historical Type in the design of contemporary Iraqi architecture
}

\author{
Fawzia Irhayyeim Hussein 1,*, and Ghada Musa Al-Silk ${ }^{2}$ \\ ${ }^{1}$ Department of Architecture, University of Baghdad, Baghdad, Iraq, fawziaasadi@coeng.uobaghdad.edu.iq \\ ${ }^{2}$ Department of Architecture, University of Baghdad, Baghdad, Iraq, mrsghada@gmail.com \\ * Corresponding author: Fawzia Irhayyeim Hussein, email: fawziaasadi@coeng.uobaghdad.edu.iq \\ Published online: 31 December 2019
}

Abstract- The appearance of the type in architecture has had a profound impact on contemporary architectural thought after the free type followed by the architecture of modernity failed to achieve continuity and communication because the modern type is not descended from a historical chain, but was determined by economic calculations, which is produced by logical processes that combine needs with techniques. Therefore, the type is considered the theoretical tool that moves architecture and is the organizer with the historical content, which can continue to achieve a culturally continuous architecture, that realizes the architects to create communicating architecture. Thus, the problem is the lack of knowledge in the method of using the historical type in the contemporary of Iraqi architecture, and to extract the most important characteristics. The aim of the research is extraction of the historical type of Iraqi architecture for the period preceding Islam (Sumerian, Assyrian, Babylonian, and Hatra) and its use in the design of contemporary Iraqi architecture. Thus, the hypothesis is the use of the historical type in contemporary Iraqi architecture creates contemporary architecture and urban continuum.

Keywords- Type, Iraqi architecture, historical type, relationship, contemporary architecture. 